\title{
1 Characterizing the Effect of an Off-Peak Ground Pre-Cool Control Strategy on Hybrid Ground Source Heat Pump Systems
}

Department of Mechanical and Industrial Engineering, Ryerson University, 350 Victoria Street

*Corresponding author: seth.dworkin@ryerson.ca 


\section{Abstract}

2 Geo-exchange systems are a sustainable alternative to conventional space conditioning systems

3 due to their high operating efficiency, resulting in reduced energy consumption and greenhouse

4 gas emissions. However, geo-exchange's ability to penetrate the market has been throttled by 5 large capital investments, resulting in undesirable payback periods. Optimized hybrid ground 6 source heat pump systems (HGSHP) systems have been introduced as a remedy to overcome the

7 current economic hurtles associated to the installation of geo-exchange systems. In both the 8 literature, as well as in practice, there still remains potential for increased economic feasibility of 9 this technology through integration of intelligent operational strategies. This paper presents a 10 novel control methodology referred to as an off-peak ground pre-cool strategy, employing a 11 time-of-use conscious operating logic which artificially pre-condition the system's bore-field. 12 Reducing peak power consumption is achieved by creating improved thermal characteristics 13 during mid-peak/peak time-of-use operating brackets. A comprehensive numerical model was 14 developed to characterize the operation of HGSHP systems for three real case studies. The model 15 implemented a base case set-point control scheme, used as a reference to assess the operational

16 benefit of the proposed off-peak ground pre-cool control strategy. The preliminary analyses 17 indicated operational cost savings of up to $16.4 \%$, under specific pre-cool scheduling. The 18 strategy indicated reductions in both carbon emission and peak power consumption of up to $19 \quad 15.0 \%$ and $58.5 \%$, respectively. In all cases increasing cooling supplied by the hybrid geo20 exchange system was indicated, with a maximum observed capacity increase of $43.7 \%$.

21 Keywords: Hybrid Ground Source Heat Pumps, Geo-Exchange, Peak Power Reduction, TOU 22 Control, Load Leveling 


\section{Introduction}

2 With building energy consumption on the rise, power conservation strategies have become a

3 global priority in many energy usage policies. Space heating and cooling contributes to a large

4 portion of a building's net energy consumption, typically accounting for $50 \%$ of a building's

5 annual usage [1, 2]. According to the U.S. energy Information Administration (EIA), the

6 building sector consumed $47.6 \%$ of the total energy in the United States, as of 2012 [3]. With

7 environmental awareness and potential resource shortages progressing to the forefront of our

8 concerns, an amplified need for sustainable alternatives will arise.

9 Geo-exchange is a term utilized in industry to describe a sustainable alternative to conventional

10 HVAC systems [4]. A geo-exchange system is also referred to as a Ground-Source Heat Pump

11 (GSHP); interchangeable terms used to describe this high efficiency earth energy technology. A

12 critical component of GSHP systems are the circulation pumps, which facilitate heat exchange

13 to/from the dwelling. Geo-exchange systems utilize ancient pumping techniques through the

14 application of modernized historical water-lifting technology [5]. By circulating a working fluid

15 through a network of piping, geo-exchange systems utilize the ground as a low temperature

16 thermal reservoir. Taking advantage of the ground's stable temperature characteristics, high

17 efficiency space heating/cooling can be accomplished. The literature clearly indicates that geo-

18 exchange should be urgently sought as a renewable energy system, stressing implementation as

19 frequently as possible $[6,7]$.

20 The current economic viability of GSHPs and associated knowledge gaps rely on several factors

21 such as: geographical location (weather patterns and soil conditions), control methodologies,

22 utility rates, and inflation rates [8]. There is great potential for GSHP systems, but due to high

23 upfront costs and long payback periods, their ability to penetrate the market has been throttled. 
1 As a result, GSHP systems are best suited for large buildings with high thermal demands in order

2 to overcome the associated capital investment [9]. The economics of geo-exchange systems

3 (compared to conventional HVAC units) depend heavily on the utility rates of natural gas and 4 electricity. The study performed by Nguyen et al. [10] highlighted that the variability in the 5 utility rates in North America have a substantial effect on the size of the resulting ground-loop 6 for a GSHP system. As a result of incremental inflation of electricity rates, GSHP systems are a 7 favourable sustainable alternative for cooling dominant buildings (those requiring more energy 8 for cooling than heating). GSHP systems show less financial incentive for heating dominant 9 buildings due to the comparatively low cost of natural gas [11, 12]. Current rules-of-thumb 10 utilized in industry for system sizing do not correspond to an optimized design, as outlined by 11 Alavy et al., [9] and Nguyen et al., [10]. Optimized hybridization is a remedy that can be 12 implemented to alleviate the high upfront costs and long payback periods associated to this 13 technology. This method couples a GSHP system with an auxiliary heating and cooling unit, or 14 in the case of a retrofitted installation, the existing conventional heating and cooling systems are 15 utilized $[8,9,10]$. HGSHP systems operate in a manner wherein the GSHP unit is sized to meet a 16 percentage of the peak heating/cooling load. In hours of peak demand, the auxiliary systems 17 provide supplementary heating/cooling to meet the building's thermal comfort requirements [13, 18 14].

19 In addition to geo-exchange hybridization, an increase in operating efficiency can be obtained 20 through the integration of an improved control paradigm; resulting in the potential for a 21 reduction in energy usage, operating costs, and green-house gas (GHG) emissions $[15,16,17$, 22 18]. Solar assisted ground source heat pump (SAGSHP) systems have been proposed in the 23 literature as an alternative hybrid system configuration, allowing for improved system efficiency. 
1 Geo-exchange system performance is heavily dependent on soil temperature, SAGSHP systems

2 allow for improved system efficiency in heating mode by a controlled increase in soil

3 temperature. Nam et al. [19] simulated the performance benefits of a SAGSHP system with a

4 predicted $28.1 \%$ and $9.3 \%$ increase in bore-field heat exchange rate and system COP,

5 respectively. Esen et al., [20] conducted a modeling and experimental performance analysis of a

6 solar-assisted GSHP utilizing a 'slinky' ground-loop configuration. Utilizing artificial neural

7 networking and adaptive neuro-fuzzy inference systems, the research indicated successful

8 application of higher level control resulting in improved hybrid solar system performance.

9 A performance assessment study [21], presented valuable insight on various research areas to

10 further the potential of geo-exchange. It highlighted time-of-use (TOU) based control strategies

11 as an area for further research and development, indicating a potential to reduce electricity costs

12 from $20-25 \%$ (excluding regulatory and distribution charges). Aside from the cost savings

13 associated to TOU control, additional benefits are provided to utilities in the form of electrical

14 load leveling, which helps alleviate the pressure placed on the grid during peak hours [21]. The

15 study presented by Carvalho et al., [22] proposed a TOU-conscious strategy; using a GSHP as a

16 flexible load to artificially consume energy in off-peak periods to pre-heat a service building.

17 The building pre-heat method allowed for a portion of the GSHP's operating cycles to be

18 isolated within off-peak brackets, taking advantage of lower electricity rates; resulting in a $34 \%$

19 reduction in electricity costs [22].

20 The aim of this paper is to propose the preliminary analysis of a new and innovative control

21 strategy for operation of HGSHP systems. Referred to as the off-peak ground pre-cool (OGPC)

22 control strategy, this technique utilizes the auxiliary cooling system as a flexible load to

23 artificially consume electricity during off-peak TOU brackets when energy costs are most 
1 economical. This analysis aims to demonstrate that a HGSHP system operated with an OGPC

2 strategy can exploit the bore-field's thermal mass with a pre-cool, creating improved thermal

3 characteristics during mid-peak/peak TOU brackets. With the additional benefit of peak power

4 reduction, introducing a pre-conditioned bore-field helps reduce peak energy consumption by

5 allowing the GSHP to supply more cooling with a higher degree of efficiency. With a TOU-

6 conscious operating strategy, the proposed methodology will not only address improving system

7 economics through an increase in operating efficiency, but also presents a multifaceted approach

8 that intends to concurrently aid the balancing of the electrical grid.

9 The presented study utilizes two software platforms to evaluate the impact of the operational

10 strategy. During the building energy simulation stage of this research the building thermal loads

11 were determined using eQuest [23], with the remaining design and numerical modeling being

12 carried out using MATLAB [24]. A MATLAB platform was selected to numerically simulate the

13 hybrid geo-exchange system due its successful application in similar research presented in the

14 literature $[25,26,27,28,29]$. Numerical simulations were conducted to predict the impact the

15 proposed strategy has on electrical energy consumption, annual operating cost, carbon emissions,

16 and peak power reduction for three pre-cool operating schedules; shoulder, peak, and full season.

17 A comparative analysis was performed for nine real buildings located in Toronto, Canada.

18 In the literature as well as in practice there still remains potential for improved hybrid geo-

19 exchange system performance through the application of alternate control strategies. With a

20 significant portion of research and industry applications still relying on classical control

21 methods, there is a pressing need for the development of alternative operational prospective [2].

22 In addition, further research and development for TOU-conscious control is stressed for geo-

23 exchange applications [21]. The objective of this study is to present and quantify the impact of a 
1 new and novel control methodology; intending to address and fill the knowledge gaps of the two

2 aforementioned voids in the literature.

\section{2. Methodology}

4 The methodology applied in this paper primarily consists of a three-part procedure, which is

5 illustrated in flowchart diagram presented in Figure 1. First, building energy simulations (BES)

6 were conducted to generate estimates of various buildings annual hourly heating and cooling

7 loads. The annual thermal loads are used as an input variable to design an optimally sized

8 HGSHP system, following the rigorous computational approached outlined in Alavy et al. [9].

9 Numerical simulations are then conducted with the aid of a performance prediction model that

10 has been newly developed to quantify the proposed off-peak ground pre-cool (OGPC) control

11 strategy's effect on the hybrid system's performance.

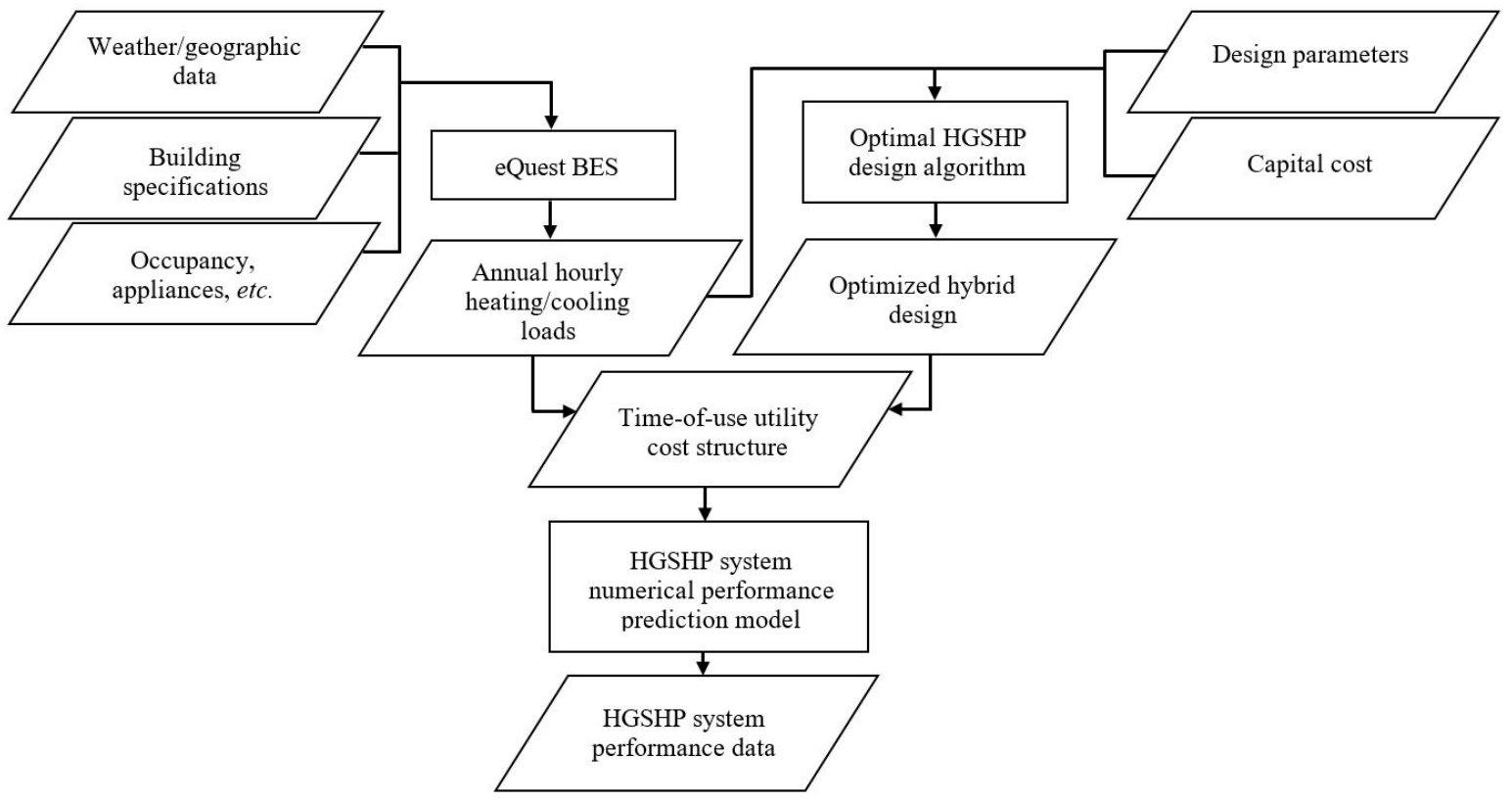


2 In this paper, annual hourly thermal loads associated the various buildings cases where generated

3 in building energy simulations using eQuest. The energy simulation initially allows for both

4 heating and cooling to be supplied in a simultaneous fashion during each time interval. However,

5 the heating and cooling loads are corrected under the assumption that each buildings internal

6 demand can be satisfied with an internal mechanisms before relying on the compensation from

7 the geo-exchange system. In our analysis a common water loop distribution system has been

8 assumed, allowing for internal load compensation to occur. For example, if an operating time

9 step has a large cooling demand and a small heating demand, the heating demand can be met by

10 removing heat from the zone requiring cooling and into the zone requiring heating. By

11 neglecting the power consumption of the internal mechanisms, the net demand will be provided

12 by the HGSHP to/from the common water loop distribution system. For the purpose of this

13 analysis, the three real buildings highlighted in Table 1 are evaluated in detail in this study. An

14 additional 6 building case computations were conducted, with the results summarized in Section

$15 \quad 3.3 .4$.

16

17

18

19 The parameters used in the HGSHP optimal design process were held constant with the analysis

20 conducted in $[9,10]$. The configuration of the ground-loop used is a closed-loop system with a

21 single U-tube vertically oriented heat exchanger per borehole, with a bore-field aspect ratio of 11

Table 1: Building information

\begin{tabular}{llll}
\hline Building & Sector & Usable Area $\left(\mathrm{m}^{2}\right)$ & Conditioned Zones \\
\hline Mid-rise, multi-residential & Residential & 15139.4 & 105 \\
High-rise, multi-residential & Residential & 16824.2 & 317 \\
School & Educational & 4525.3 & 52 \\
\hline
\end{tabular}


1 across by 4 down. The following Table 2 provides a summary of the parameters utilized in the

2 design process.

Table 2: Design parameter summary

4

\begin{tabular}{ll}
\hline Parameters & Value \\
\hline $\begin{array}{l}\text { Cooling design entering sink } \\
\text { temperature }\end{array}$ & $25.1^{\circ} \mathrm{C}$ \\
$\begin{array}{l}\text { Heating design entering source } \\
\text { temperature }\end{array}$ & $1.7^{\circ} \mathrm{C}$ \\
Heat Pump & ClimateMaster Tranquility TT \\
Soil thermal conductivity & $2.94 \mathrm{~W} / \mathrm{m} \mathrm{K}$ \\
Soil thermal diffusivity & $0.072 \mathrm{~m}^{2} /$ day \\
Duration of operation & 20 years \\
Borehole thermal resistance & $0.136 \mathrm{~m} \mathrm{~K} / \mathrm{W}$ \\
Pipe resistance & $0.06 \mathrm{~m} \mathrm{~K} / \mathrm{W}$ \\
Pipe size & $32 \mathrm{~mm}$ \\
Borehole diameter & $127 \mathrm{~mm}$ \\
Grout thermal conductivity & $1.47 \mathrm{~W} / \mathrm{m} \mathrm{K}$ \\
Number boreholes across & 11 \\
Number of boreholes down & 4 \\
Inflation rate & $4 \%$ \\
Interest rate & $8 \%$ \\
\hline
\end{tabular}

6 The heat pump selected for the hybrid system is the ClimateMaster Tranquility Series TT with an 7 assumed fixed COP of 3.1 and EER of 13.6. For the HGSHP system design the ClimateMaster 8 Tranquility TT heat pump (HP) is considered, were the heat pump is a dual stage unit capable of 9 full load and $67 \%$ part load operation. A dual stage HP was selected in this study after consulting 10 with GeoSource Energy Inc. personnel [30], stating that this is the most commonly encountered 11 HP configuration in the Southern Ontario, Canada market.

12 The auxiliary cooling system selected is a non-reversible air-source heat pump (water-air) with an 13 assumed fixed EER of 10.8 [31]. The auxiliary heating system is a natural gas furnace, with an 14 assumed fixed efficiency of $78 \%$, held constant with the design specifications outlined in [10]. 
1 The following capital cost parameters were held constant with $[9,10]$ and is summarized in Table 3.

Table 3: General capital cost of hybrid system components

4

\begin{tabular}{ll}
\hline Item & Cost \\
\hline $\begin{array}{l}\text { Ground heat exchanger (install and } \\
\text { materials) }\end{array}$ & $\$ 65.5 / \mathrm{m}$ \\
$\begin{array}{l}\text { Auxiliary cooling system, plate heat } \\
\text { exchanger including controls and }\end{array}$ & $\begin{array}{l}\$ 14 / \mathrm{kW} \text { of auxiliary cooling design } \\
\text { capacity }\end{array}$ \\
$\begin{array}{l}\text { Auxiliary equipment } \\
\text { Auxiliary heating system }\end{array}$ & $\begin{array}{l}\$ 20 / \mathrm{kW} \text { of auxiliary heating design } \\
\text { capacity }\end{array}$ \\
\hline
\end{tabular}

\subsection{Numerical Model}

7 In this study, in order to simulate and analyze the off-peak ground pre-cool control strategy, a

8 numerical model was developed using MATLAB to characterize the operation of a HGSHP

9 system. The model was developed in a modular manner allowing for simple manipulation of the

10 systems control algorithms, providing flexibility for modification and study of the proposed

11 control techniques.

12 The numerical model was developed to simulate the operation of HGSHP system (GSHP and 13 auxiliary HVAC systems) in working conditions for a year long duration. A yearly operational 14 analysis was selected over a commonly used 20 year life cycle because the annual savings of the 15 proposed control scheme was being assessed, which was more clearly realized with the selected

16 time frame. The numerical model simulates a load based analysis determining which mechanical 17 system has operational authority in each simulated time step. The model runs a yearly simulation 18 with a time-step of a third of an hour for a total of 26,280 iterations. 
1 The procedure that the numerical model follows is presented in the flowchart schematic in the

2 following Figure 2. When the algorithm is initiated, all input parameters are specified, such as

3 annual hourly heating/cooling loads (eQuest BES), optimal HGSHP system specifications

4 (design procedure from [9]), and time-of-use electrical cost structure. The input data is then

5 processed to determine important characteristics of the buildings thermal requirements, such as

6 total heating/cooling demand required, peak heating/cooling loads, and whether the building

7 under consideration is heating or cooling dominant. The capacities of the GSHP and auxiliary

8 systems are then determined based of the optimal shave factor $(\propto)$, defined as the percentage of

9 peak cooling demand met by the geo-exchange system, with the remaining load $(1-\propto)$ being

10 supplemented by the auxiliary systems. A numerical simulation of an optimally sized HGSHP

11 system operating for one year is then initiated, with a set-point control algorithm fitted to the

12 model to determine the operational authority of the sub-systems depending on the buildings

13 thermal requirement in the current time-step. For every time-step of the numerical simulation the

14 portion of demand supplied by the geo-exchange system and the auxiliary systems are

15 determined; the variation in the GSHP COP, and bore-field/entering source fluid thermal

16 response are predicted simultaneously, with this function being explained later. Once the

17 simulation expires, a data post-processing procedure is carried out to determine the resulting

18 performance of the HGSHP system over a year of operation, upon completion of this process the

19 program is terminated. 


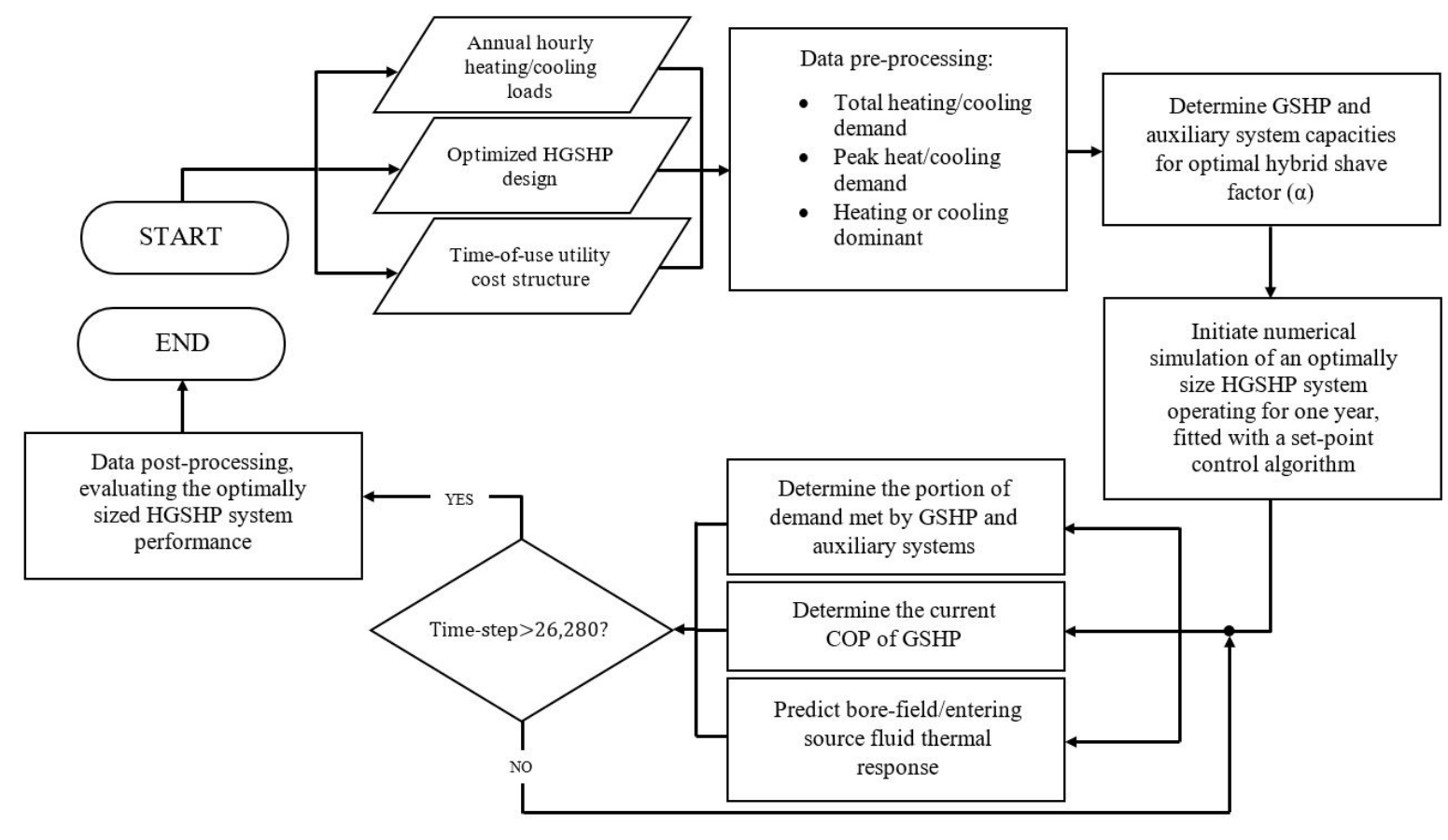

Figure 2: Process flowchart of the numerical performance prediction model

\subsubsection{Variable COP Characterization}

5 In [32], Alzahrani conducted a detailed experimental performance analysis of a GSHP system coupled to both a vertical and horizontal ground-loop at the TRCA Archetype Sustainable Twin

7 Houses located in Vaughan, Canada. An observation made in this study highlighted that a heat

8 pumps COP varies substantially with respect to system cycle time. From the raw data collected, a

9 clear correlation was represented; as the cycle on-time increases, the heat pump COP decreases,

10 observing that the GSHP experiences peak COPs during the early transient portion of the on

11 cycle [32]. This occurrence is attributed to the ground-loop working fluid, as well as the soil

12 having a large thermal inertia when the two media have thermally equilibrated. For example, in

13 cooling mode operation in the early transient stage of an on cycle, assuming the ground-loop

14 working fluid has equilibrated with the soil temperature, results in a low inlet source temperature

15 to the heat pump. As the cooling cycle progresses the local ground temperatures rise, as heat is 
1 being injected into the ground, resulting in an increasing inlet source temperature. In cooling

2 mode operation as the cycle duration increases, local ground temperature increases and

3 consequently inlet source temperature increases. This results in and increase in GSHP system's

4 compressor power consumption, resulting in a decrease in system COP [32].

5 A GSHPs cycle time plays a vital role in system performance; as the cooling cycle duration 6 increases and entering source temperature increases, resulting in greater HP compensation to 7 maintain load requirements. Utilizing the experimental data collected by Alzahrani in [32], a 8 variable COP correlation was developed to characterize the GSHP systems COP as a function of 9 the on cycle duration. The following Figure 3 is an illustration of the correlations utilized 10 to characterize the geo-exchange systems COP with cycle time.

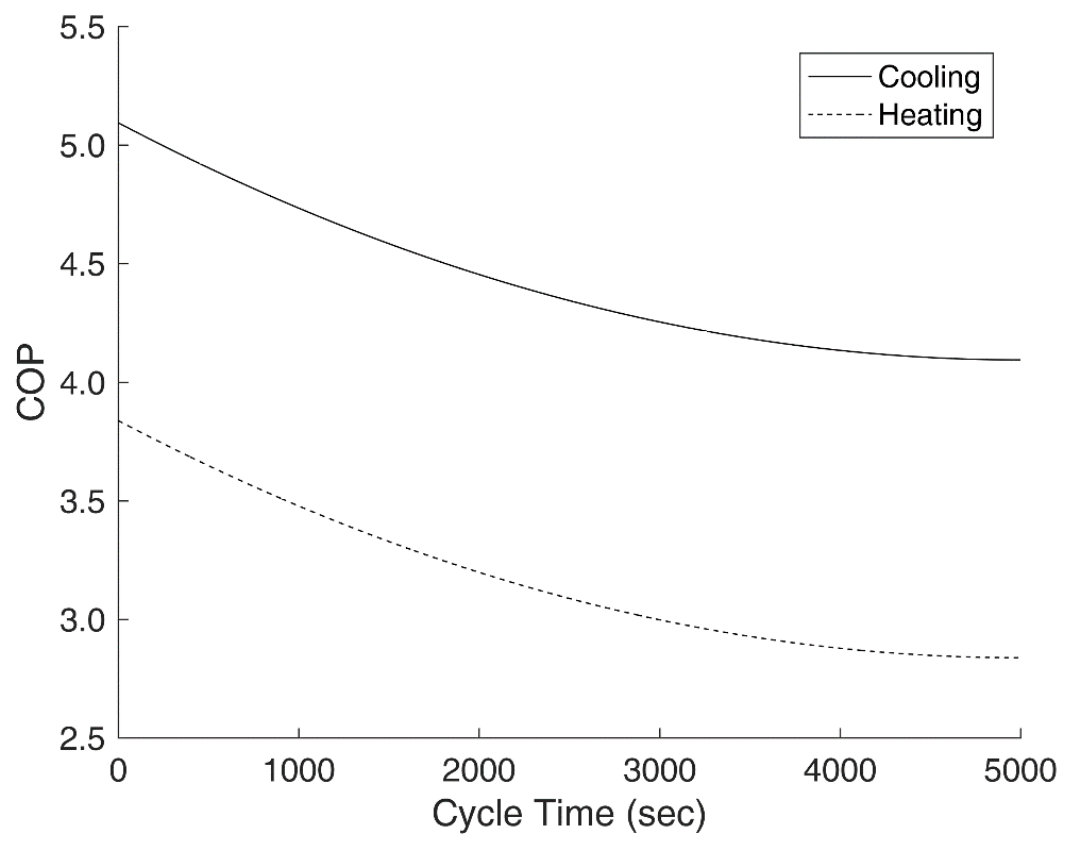

14 The variable COP output ranges from 5.07-4.09 in cooling mode and 3.84-2.83 in heating mode, 15 following a descending polynomial regression with coefficients of determination exceeding 0.8 . 
1 As evident from the COP ranges, the GSHP system is more efficient in cooling mode operation

2 when compared to heating mode. The higher efficiency is due to smaller temperature difference

3 requirements between entering load and sink temperatures to meet thermal demands.

4 A thermal continuity condition was assumed upon integration of the presented performance 5 correlations. This continuity assumption implies that the ground-loop fluid has a thermal 6 recharge time that is equal to the previous on-cycle duration. For example, if the GSHP is 7 operating for one on-cycle time-step, it takes one off-cycle time-step for the two media to reach 8 steady-state. Thus when the heat pump's on-time is equal to the systems off-time the ground and 9 ground-loop working fluid is assumed to have thermally equilibrated.

11 The 2015 TOU utility structure from Toronto, Canada was adopted as a means to estimate the 12 cost savings associated with the application of the OGPC control technique. TOU brackets are 13 used as a primary control variable in the OGPC algorithm in an attempt to reduce peak power 14 consumption to ease pressure on the grid during high-demand hours, reduce GHG emissions, and 15 decrease annual operating cost in cooling mode. The following Table 4 presents the TOU 16 brackets and electricity rates used in the numerical simulations presented in this paper. 
Table 4: TOU electricity rates Ontario 2015 [33]

\begin{tabular}{llll}
\hline Period Type & Rate $(\varnothing / \mathrm{kWh})$ & Summer Periods & Winter Periods \\
\hline Peak & 16.1 & 11 a.m. -5 p.m. & 7 a.m. -11 a.m. \\
& 12.2 & & 5 p.m. -7 p.m. \\
Mid-Peak & & 7 a.m. -11 a.m. & 11 a.m. -5 p.m. \\
& 5.0 & 7 p.m. -7 p.m. & \\
Off-Peak & 7 p.m. -7 a.m. & 7 p.m. -7 a.m. \\
\hline
\end{tabular}

4 The Ontario Energy Board (OEB) classifies two peak seasons; summer weekdays ranging from

5 May $1^{\text {st }}$ to October $31^{\text {st }}$, and winter weekdays ranging from November $1^{\text {st }}$ to April $30^{\text {th }}$. For

6 weekends and holidays, an off-peak rate is designated for the full day [33].

\subsection{3. $\mathrm{CO}_{2}$ Emissions}

8 The total annual $\mathrm{CO}_{2}$ emissions associated to the operation of a HGSHP system are dependent on

9 the electricity consumed by the GSHP, the auxiliary systems, and the $\mathrm{CO}_{2}$ emissions factors for

10 the local electricity supply mix. The electricity supply mix breakdown used in this analysis

11 corresponds to Ontario's power generation data for 2015. Over the 2015 year, Ontario, Canada's

12 average supply mix is categorized into the following sources: $60.56 \%$ from nuclear, $23.28 \%$

13 form hydroelectricity, $9.96 \%$ from natural gas, $5.77 \%$ from wind, $0.10 \%$ from solar, and $0.23 \%$

14 from biofuel [34].

15 In this analysis, the 2015 hourly electricity supply mix for Ontario is used to produce an average

16 hourly $\mathrm{CO}_{2}$ emissions factor. In each numerical time-step, the supply mix factors for the

17 aforementioned energy sources are determined. The product of each supply mix factor and their 18 corresponding fuel type emissions factor is computed. The summation of the product of each 19 supply mix factor and corresponding fuel type emissions factor produces an average hourly $\mathrm{CO}_{2}$ 20 emissions factor. This process is iterated 8760 times, corresponding to each of the 8760 hours in 
1 2015. The result of this computation is used to predict the amount of $\mathrm{CO}_{2}$ emitted $(\mathrm{kg})$, for the

2 operation of the HGSHP system. Utilizing an hourly average $\mathrm{CO}_{2}$ emissions factor in the

3 computation allows for the ability to evaluate the potential impact that the proposed peak power

4 shaving strategy poses on annual emissions for the three building cases.

5 In the present study, the $\mathrm{CO}_{2}$ emissions factors are in terms of $\mathrm{kg}-\mathrm{CO}_{2}$ per $\mathrm{kWh}\left(\mathrm{kg}-\mathrm{CO}_{2} / \mathrm{kWh}\right)$

6 of electricity consumed. The emissions factors used in this analysis are $0.002 \mathrm{~kg}-\mathrm{CO}_{2} / \mathrm{kWh}$ for

7 nuclear power [35], $0.023 \mathrm{~kg}-\mathrm{CO}_{2} / \mathrm{kWh}$ for hydroelectricity [35], $0.553 \mathrm{~kg}-\mathrm{CO}_{2} / \mathrm{kWh}$ for natural

8 gas [36], $0.002 \mathrm{~kg}-\mathrm{CO}_{2} / \mathrm{kWh}$ for wind power [35], $0.035 \mathrm{~kg}-\mathrm{CO}_{2} / \mathrm{kWh}$ for solar power [37], and

$9 \quad 0.0261 \mathrm{~kg}-\mathrm{CO}_{2} / \mathrm{kWh}$ for biofuel [38]. The biofuel emissions factor is determined by taking the

10 average for wood chips $\left(0.0149 \mathrm{~kg}-\mathrm{CO}_{2} / \mathrm{kWh}\right)$ and wood pellets $\left(0.0373 \mathrm{~kg}-\mathrm{CO}_{2} / \mathrm{kWh}\right)$,

11 assuming equal mix of the two sources [38].

\subsubsection{Off-Peak Ground Pre-Cool (OGPC) Control Strategy}

13 HGSHP systems are commonly connected either in a parallel or series configuration, depending 14 on system operational requirements [39]. The proposed physical system orientation required to 15 implement a ground pre-cool is illustrated in a system schematic in Figure 4.

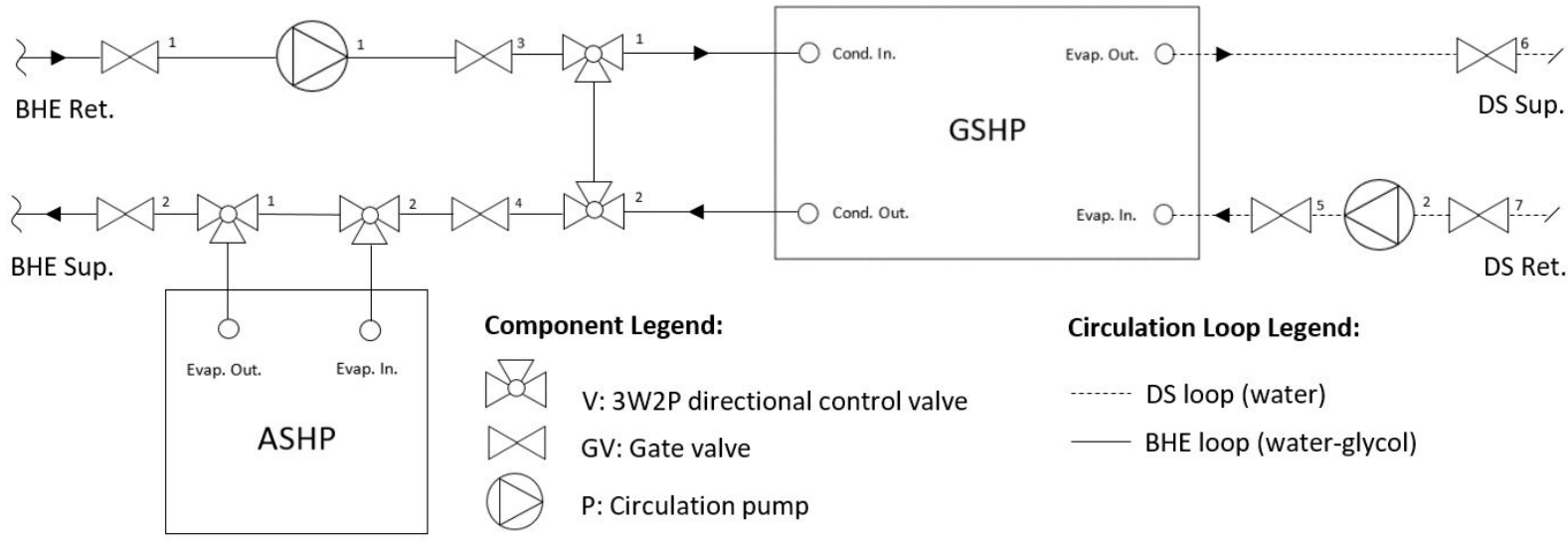


1 The hybrid geo-exchange system uses a series connection of the ASHP with the ground-loop.

2 Utilizing this configuration allows for three operating loops, through the manipulation of four 3 three-way-two-position directional control valves (V1 - V4). Loop one is activated under base 4 load operating conditions, where the GSHP unit is the only active load coupled to the bore-field 5 heat exchanger (BHE). Loop one is the primary circulation loop, accomplished when V1 - V4 6 are in their rest state. Loop two is activated under peak operating conditions, when the GSHP and 7 ASHP are both active loads, interacting with the BHE to supply the building's thermal demand. 8 Loop two is accomplished by actuating V1 and V2 into their flow diverting state, allowing for 9 the BHE fluid to be circulated through the auxiliary ASHP's evaporator. Loop three is activated 10 for OGPC operation, resulting in the ASHP being the only active load interacting with the BHE. 11 Loop 3 circulation is accomplished by actuating V1 - V4 into their flow diverting state, 12 decoupling the GSHP from the BHE circuit.

13 The primary control technique used in the operation of the HGSHP system is a conventional set14 point control scheme. A set-point control strategy is utilized as a base case scheme to compare 15 system performance benefits that an OGPC has on the operation of a HGSHP system. The OGPC 16 algorithm's operational authority is restricted to the control of only the ASHP, under the 17 condition that specific logic indicators are satisfied.

18 The OGPC strategy utilizes two control variables to determine the beginning of an OGPC cycle, 19 the control variables being: time of the year and TOU operating bracket. The time of year was 20 utilized as a control variable in the OGPC algorithm to permit flexibility in pre-cool operation, 21 allowing for time spans of various cooling load densities to be targeted by the algorithm. In this 22 study, three operating durations were analyzed; shoulder season (SS) operation schedule (April $231^{\text {st }}-$ May $31^{\text {st }}$ ), peak season (PS) operation schedule (July $1^{\text {st }}-$ August $31^{\text {st }}$ ), and full season (FS) 
1 operation schedule (April $1^{\text {st }}-$ August $31^{\text {st }}$ ). The TOU control variable is used in the OGPC

2 algorithm to restrict pre-cooling to off-peak TOU brackets, taking full advantage of low

3 electrical energy prices.

4 The following Figure 5 presents a flowchart diagram outlining the OGPC control logic. For 5 every iteration of the numerical model, the OGPC algorithm evaluates the state of the two 6 control variables. First the algorithm considers the time of year, attempting to classify the current 7 time-step into one of the three proposed pre-cool schedules; represented by the first three 8 decision blocks (FS, SS, and PS schedule) illustrated in Figure 5. If none of the three decision 9 blocks are satisfied, the HGSHP system maintains primary operation. Once the algorithm 10 determines that the current time-step satisfies the requirements of one of the three proposed 11 schedules, the next control variable is evaluated. The second control variable considers the hour 12 of operation, attempting to classify the current time-step into one of the three TOU operating 13 brackets; represented by the fourth decision block in the logic flowchart presented in Figure 5. 14 The fourth decision block in Figure 5 indicates a time range from 19:00-7:00 hours, which refers 15 to an off-peak TOU bracket for the adopted utility rate structure presented in Table 4 . When both 16 logic conditions are satisfied, a pre-cool cycle is initiated. First the bore-field circulation loop 3 17 is activated, represented by the first process block in Figure 5; resulting in the GSHP being 18 decoupled form the ground-loop, with the only active load being the ASHP. The ASHP is then 19 initiated to operate at full load for a pre-cool cycle; represented by the second process block in 20 Figure 5. 


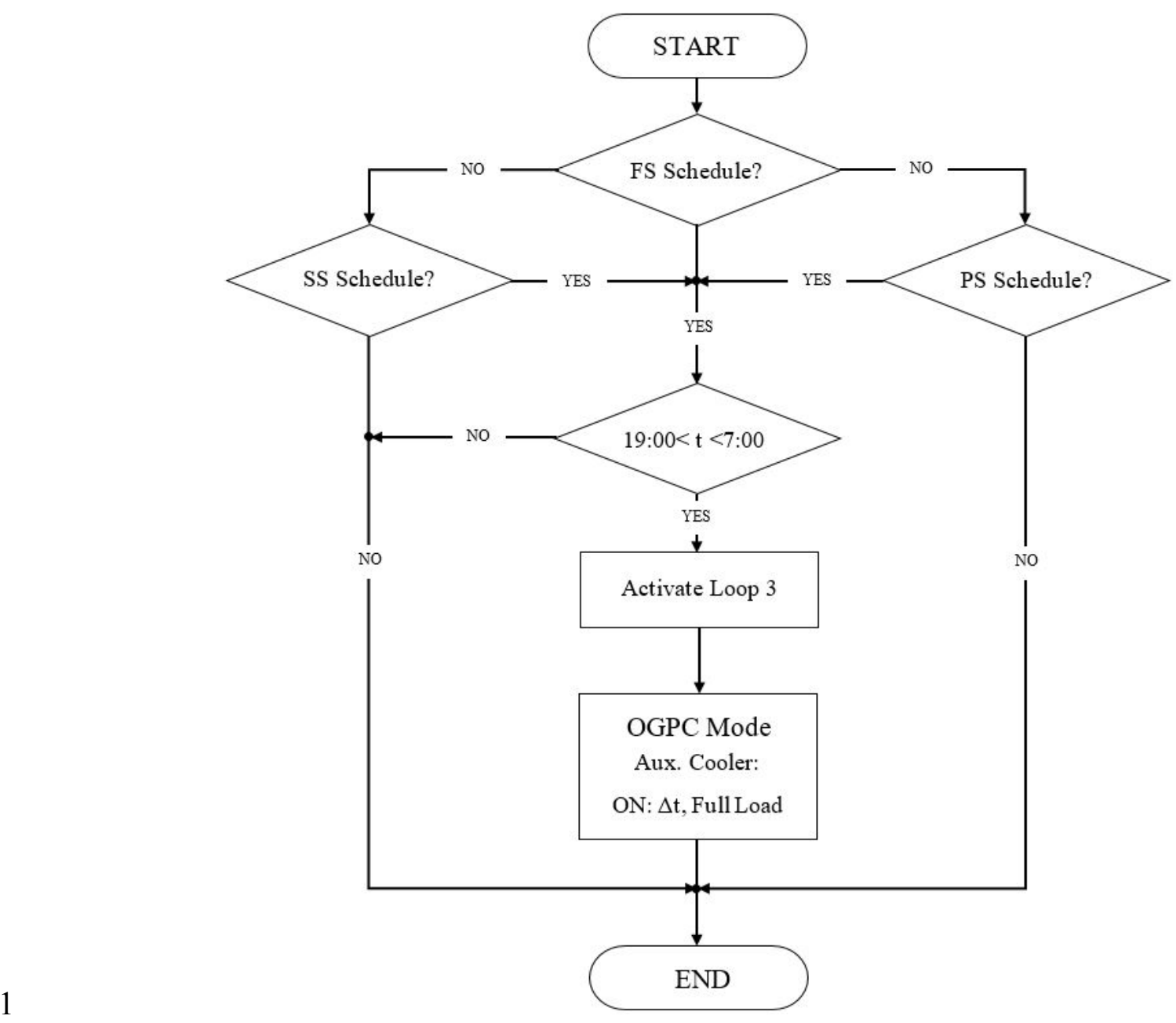

Figure 5: Flowchart diagram of simplified pre-cool control logic

3 To characterize the bore-field/ground's thermal response to an OGPC, the results presented in

4 the study conducted by Nam et al. [19] were used. In [19], a performance predication model was

5 developed to analyze a solar-assisted GSHP (SAGSHP), using TRNSYS [40]. In [19], a solar

6 thermal collector was used to implement a ground pre-heat thermal storage strategy to enhance

7 the performance of the GSHP system. The numerical model for the vertical U-tube ground

8 exchanger (DST model) that were used in [19]. From the results presented in [19], four

9 correlations were developed to characterize the bore-field thermal response to

10 injection/extraction, cooling output and COP variation in response to inlet source temperature 
1 change. The correlations were developed in the form of linear regressions, with this assumption

2 being validated based off of the experimental correlations presented in [32].

3 The present model simulates two assumed physical responses to the thermal benefit resulting

4 from the OGPC; an increase in the rate of heat injection to the ground during cooling operation

5 (increase in cooling output) and an increase in the GSHP system COP. The increase in cooling

6 output is due to the reduction in the sink temperature, resulting in an average increase in heat

7 injection per meter length of the ground-loop. The increase in heat pump COP in cooling mode is

8 a result of a reduction in inlet source temperature, resulting in the reduction compressor power

9 consumption. These assumptions were validated by the studies presented in both [19] and [32],

10 which provide both an experimental and numerical confirmation.

11 The presented numerical model predicts the GSHP system's performance by means of Eq. 1 and

12 Eq. 2; in which $Q_{G S H P}$ and $C O P_{G S H P}$ are the resulting heat output and system efficiency,

13 respectively. In Eq. 1, the product of $\propto$ and $C L_{\max }$ represents the base load supplied by the GSHP

14 (system's cooling capacity), where $C L_{\max }$ is the peak cooling load and $\alpha$ is defined as the shave

15 factor, which is the percentage of the peak load met by the GSHP. The $\Delta Q_{\text {out }}$ term is the

16 incremental increase in the system's heat injection to the ground when exposed to a pre-cooled

17 bore-field. The magnitude of the thermal capacity increase is predicted by the aforementioned

18 cooling output correlation generated from the results presented in [19].

$$
Q_{G S H P}=\propto \cdot C L_{\max }+\Delta Q_{\text {out }}
$$

20 In Eq. 2, the $C O P_{\Delta t}$ terms represent the variation of the HP efficiency during transient operation,

21 which is characterized by the cooling curve presented in Figure 3. The $\triangle C O P$ term

22 represents the incremental increase in system performance when exposed to a pre-cooled bore- 
1 field. The magnitude of the $\triangle C O P$ term is quantified by the aforementioned COP correlation

2 generated from the results presented in [19].

$$
C O P_{G S H P}=C O P_{\triangle t}+\triangle C O P
$$

4 Eq. 3, Eq. 4 and Eq. 5 are used to estimate the operational performance of the auxiliary cooling 5 system, where $Q_{A U X}$ and $C O P_{A U X}$ are the resulting heat output and system efficiency, 6 respectively. Eq. 3 defines the auxiliary system's cooling capacity, sized to provide 7 supplementary cooling under peak operating conditions. The proposed model simulates the 8 auxiliary cooling unit as a single-stage fixed capacity system.

$$
Q_{A U X}=(1-\propto) \cdot C L_{\max }
$$

10 Eq. 4 introduces the variable $f_{P C}$, which is the auxiliary system performance correction factor.

11 The magnitude of $f_{P C}$ is determined by implementing the step function in Eq. 5. The $f_{P C}$ factor is 12 a value of 1.0 when the simulated system is operating within a mid-peak to peak TOU bracket, or 13 a value of 1.5 when operating within an off-peak TOU bracket. A performance correction factor 14 has been introduced to modify the auxiliary systems performance when operating during an off15 peak TOU bracket to account for improved operating conditions. It is assumed that on average 16 there is a $50 \%$ improvement in auxiliary system COP when operating in an off-peak TOU 17 bracket, when compared to mid-peak and peak durations. This assumption was justified as the 18 average daily maximum to minimum dry bulb temperature difference for a cooling season in 19 Toronto was $8{ }^{\circ} \mathrm{C}$, the average difference in maximum to minimum relative humidity is 20 approximately $30 \%$ [41]. It is noted that in a cooling season, maximum temperature and 21 humidity occur primarily in a peak TOU bracket, while minima occur during off-peak durations.

$$
C O P_{A U X}=f_{P C} \cdot C O P_{A U X}
$$


1 Where,

$$
f_{P C}=\left\{\begin{array}{l}
1.0, t \rightarrow \text { mid }- \text { peak or peak } \\
1.5, t \rightarrow \text { off }- \text { peak }
\end{array}\right.
$$

\section{Results}

4 The numerical performance prediction model developed in this research considers full seasonal

5 operation (both heating/cooling). However, only cooling season operating results are presented

6 in this section, as the proposed OGPC strategy's scope is limited to impacting system

7 performance in cooling mode operation. The results from this study are presented as follows:

8 building load characteristics/ hybrid system specifications, base case control strategy, shoulder

9 season operation, peak season operation, and full season operation.

\subsection{Building Loads and Hybrid System Specifications}

11 In this study, three buildings were considered: a mid-rise (MR) multi-residential facility, high12 rise (HR) multi-residential facility, and a school. Each of the buildings utilized in the research

13 are real, and either had a GSHP installed or considered $[9,10]$. The following Figure 6 illustrates

14 the predicted building thermal loads as a result of the BES conducted on eQuest. In Figure 6, the

15 cooling demand is presented as a positive load (light gray lines) and the heating demand is

16 presented as a negative load (dark gray lines). The three presented building cases are all cooling

17 dominant facilities, where the peak demand for cooling is greater than the heating requirement.

18 Both the mid-rise (Figure 6a) and high-rise (Figure 6b) facilities require substantially greater 19 amounts of cooling than heating, where the school's (Figure 6c) total cooling and heating 20 requirements are comparatively even. In Figure $6 \mathrm{c}$, the unique cooling demand distribution is 21 attributed to the specific occupancy pattern distinctive to an educational institution, with a 
1 reduction in occupants occurring in peak summer months (end of June to the beginning of

2 September).
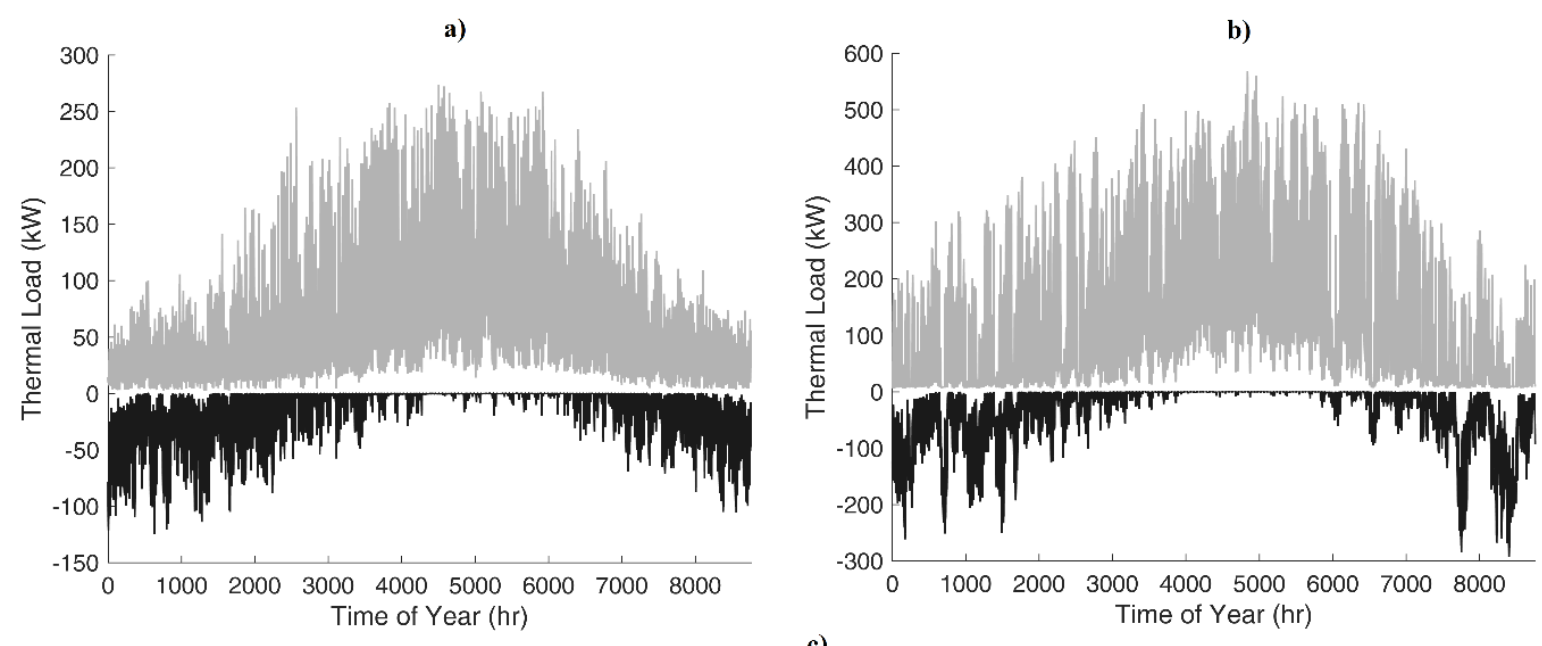

c)

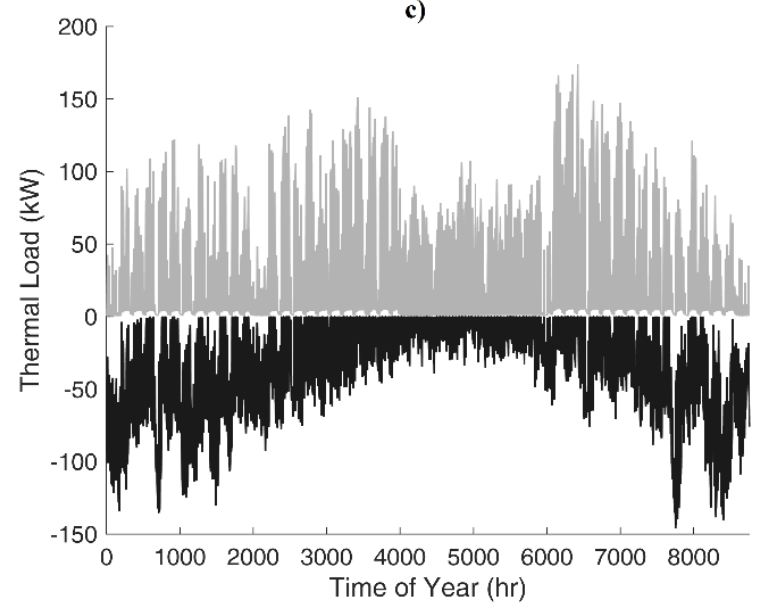

Figure 6: Predicted thermal loads for buildings (a) mid-rise, (b) high-rise, and (c) school

6 With the hourly loads presented in Figure 6, the design methodology presented in [9] was

7 conducted to optimally size the hybrid geo-exchange systems for the three presented cases. Table

85 presents a summary of important details of the building thermal characteristics and hybrid geo-

9 exchange systems specifications for the mid-rise, high-rise, and school buildings. Referring

10 Table 5, it can be seen the annual total heating demand (THD) to total cooling demand (TCD) 
1 ratios reveal both the mid-rise and high-rise buildings are thermally imbalanced requiring four

2 times the amount of cooling as they do heating, with the school being relatively balanced. 4 5

\begin{tabular}{ccccccc}
\hline Building & $\begin{array}{c}\text { Peak Cooling } \\
\text { Load }(\mathrm{kW})\end{array}$ & $\begin{array}{c}\text { Shave Factor } \\
(\alpha)\end{array}$ & $\begin{array}{c}\text { Ground-Loop } \\
\text { Length }(\mathrm{m})\end{array}$ & $\begin{array}{c}\text { THD } \\
(\mathrm{MWh})\end{array}$ & $\begin{array}{c}\text { TCD } \\
(\mathrm{MWh})\end{array}$ & THD/TCD \\
\hline Mid-Rise & 274.5 & 0.23 & 2115.5 & 143.0 & 573.7 & 0.25 \\
High-Rise & 568.4 & 0.21 & 3920.5 & 315.7 & 1212.2 & 0.26 \\
School & 174.0 & 0.21 & 791.9 & 295.9 & 252.1 & 1.17 \\
\hline
\end{tabular}

6
3 Table 5: Summary of building/hybrid system characteristics for a mid-rise, high-rise, and a school building$$
\text { school building }
$$

\subsection{Base Case Set-Point Control Strategy}

The numerical performance prediction model was fitted with a standard set-point control strategy to develop a baseline result in which to compare the proposed OGPC operating strategy. The base case strategy utilizes the GSHP as the primary mechanical system, meeting base load demand and is only assisted by the auxiliary cooling system when the demand exceeds the GSHP systems capacity. Table 6 represents the predicted hybrid system performance over a year of operation when the system is controlled with a standard set-point control scheme. The annual cooling cost (ACC) is given in Canadian dollars, the annual electrical consumption for cooling (AECC) is presented in terms of megawatt hours, and the annual carbon emissions (ACE) is presented in terms of kilograms of $\mathrm{CO}_{2}$. The total cooling demand met (TCDM) given in terms

of a percentage, representing the portion of cooling load supplied by the GSHP system. In Table

6 it can be seen that the under-sized hybrid systems are still capable of meeting a large portion of 9 the total cooling requirement of each of the three presented buildings. 
Table 6: Hybrid system performance for a year of operation with a set-point control strategy

\begin{tabular}{ccccc}
\hline Building & ACC $(\$)$ & $\begin{array}{c}\text { AECC } \\
(\mathrm{MWh})\end{array}$ & ACE $\left(\mathrm{kg}-\mathrm{CO}_{2}\right)$ & TCDM (\%) \\
\hline Mid-Rise & 20381 & 185.4 & 12694 & 41.7 \\
High-Rise & 48127 & 423.3 & 29231 & 35.9 \\
School & 8791 & 75.8 & 5374 & 34.5 \\
\hline
\end{tabular}

4 In Table 7, a summary of the energy consumption distributed over the TOU operating brackets is

5 presented for the three building cases operated with a set-point control strategy. It can be seen

6 that the mid-peak and peak hours of consumption account for a $48.53 \%, 55.49 \%$, and $58.66 \%$ of

7 total yearly energy consumption from space cooling for the mid-rise, high-rise, and school,

8 respectively. It is noted that the higher consumption occurring in the off-peak TOU bracket is

9 attributed to inclusion of weekend/holiday operation, which is categorized in the off-peak cost

10 bracket.

11 Table 7: Summary of power consumption in TOU brackets, for a year of cooling operation with 12 13 a set-point control strategy

\begin{tabular}{cccc}
\hline Building & Off-Peak (MWh) & Mid-Peak (MWh) & Peak (MWh) \\
\hline Mid-Rise & 95.4 & 44.6 & 45.3 \\
High-Rise & 188.4 & 122.1 & 112.8 \\
School & 31.3 & 22.5 & 22.9 \\
\hline
\end{tabular}

14 


\subsection{OGPC Control Strategy}

2 To characterize the effect of the OGPC control strategy on the presented hybrid geo-exchange 3 systems, a primary analysis was conducted where 36 different annual simulations were carried

4 out, with only the pre-cool duration being varied. The simulations where conducted with 20

5 minute increments of pre-cool time, up to a maximum of 12 hours (full off-peak operating

6 bracket). Upon completion of this study, the OGPC strategy was analyzed to determine the peak

7 power reduction capability, resulting from the thermal benefit of the pre-conditioned bore-field.

$8 \quad 3.3 .1 \quad$ Shoulder Season Operation

9 The simulated results for OGPC control strategy restricted to SS operation are presented in 10 Figure 7. Figure 7 presents the variation in AECC and ACC with respect to pre-cool duration. 11 Each data point represents an annual cooling season simulation, with the horizontal line acting as 12 a datum reference for the same system operating without an OGPC scheme. Note that the 13 fluctuation in the simulated data for both AECC and ACC occurs because of the simplicity of the 14 set-point control algorithm operating the hybrid geo-exchange, resulting in set-point overshoot. 

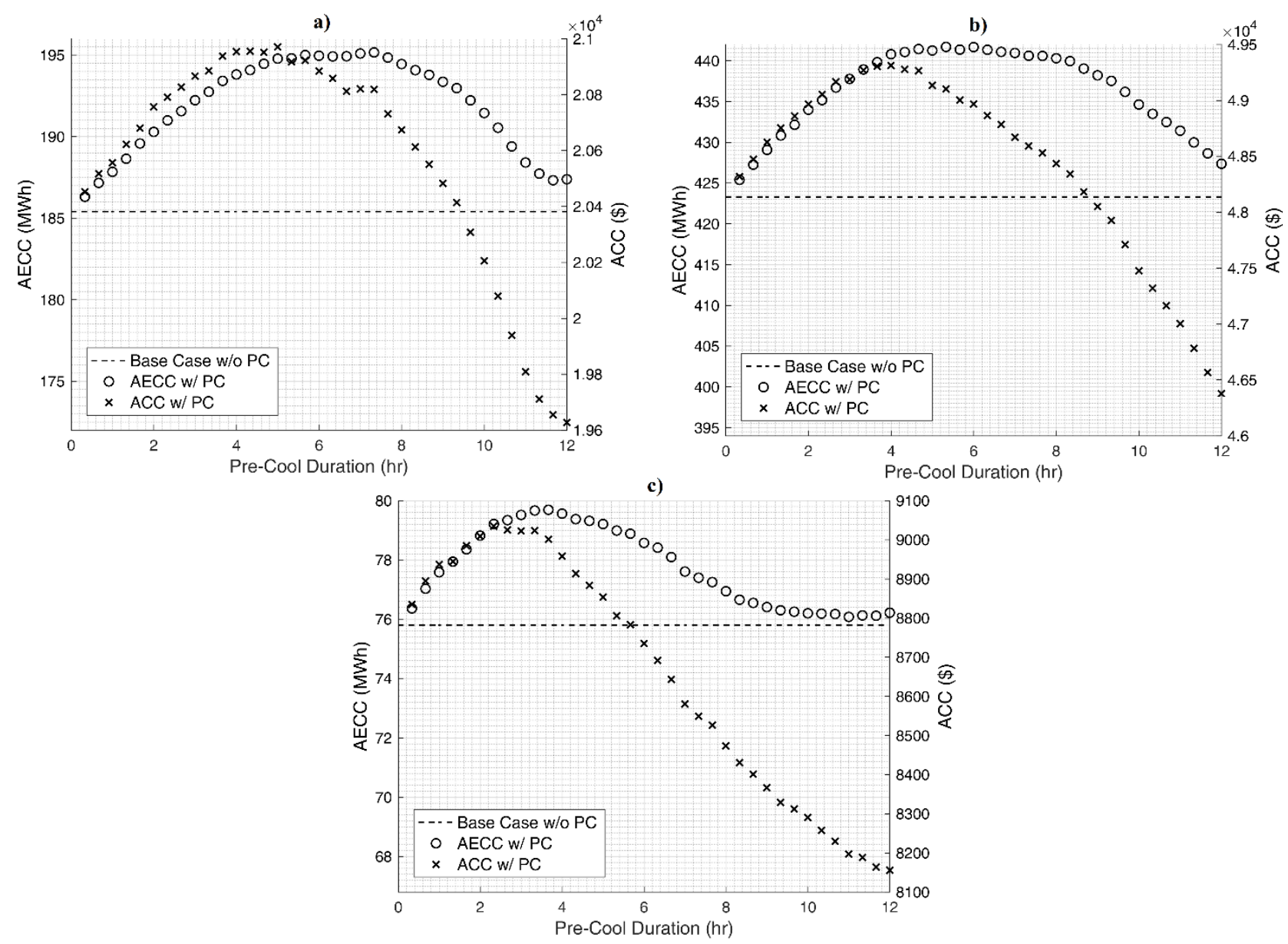

2 Figure 7: AECC and ACC for SS operation versus pre-cool duration for buildings (a) mid-rise,

5 The impact the OGPC strategy has on the three present cases is clearly characterized in Figure 7.

6 All three cases depict a similar trend, in which energy consumption increases for small periods of

7 bore-field pre-conditioning. After reaching a peak in annual energy consumption, all three

8 systems begin to experience the thermal benefit imposed by longer periods of pre-cool. The mid-

9 rise (Figure 7a) and high-rise (Figure 7b), required longer periods of pre-conditioning before a

10 positive impact was realized on system energy consumption; approximately seven and six hours,

11 respectively. When analyzing Figure $7 \mathrm{c}$ it can be seen that the school required approximately

12 three hours of pre-cool before the systems operation conditions where improved enough to 
1 reduce energy consumption. For all three cases, the greatest impact on energy consumption

2 occurs at approximately 12 hours (maximum pre-cool duration), resulting in minor increases in

3 AECC: $1.0 \%, 0.9 \%$, and $0.3 \%$ for the mid-rise, high-rise, and school, respectively.

4 Implementing the TOU structure presented in Section 2.2.2, the annual cooling cost was

5 determined for the three presented cases operating within a shoulder season period. Both the

6 mid-rise (Figure 7a) and high-rise (Figure 7b) required a minimum pre-cool duration of

7 approximately nine hours to break even with the operating cost associated with the base case

8 control scheme. The school (Error! Reference source not found.Figure 7c) showed financial

9 gain for a pre-cool duration of only five hours. The largest ACC savings accomplished for all

10 three buildings were realized for a full 12 hour pre-cool, accomplishing ACC savings of: $3.7 \%$,

$113.6 \%$, and $7.2 \%$ for the mid-rise, high-rise, and school, respectively.

12 The potential for cost savings is accomplished by the proposed methodology's ability to shift a

13 percentage of mid-peak/peak power consumption into off-peak TOU brackets, taking advantage

14 of the low electricity cost. Table 8 summarizes the mid-peak/peak power reduction potential for

15 the shoulder season pre-cool schedule. All three buildings show significant mid-peak/peak

16 reduction potential, resulting in $16.6 \% / 16.3 \%, 14.9 \% / 14.4 \%$, and $24.7 \% / 24.4 \%$, for the mid-

17 rise, high-rise, and school, respectively. The school indicates a greater benefit from a peak power

18 reduction prospective because is has a smaller hybrid system compared to the mid-rise and high-

19 rise buildings. With a smaller hybrid system (smaller bore-field/soil volumes) the thermal impact

20 of the pre-cool strategy is active for longer durations, allowing for the school to realize a greater

21 peak shaving benefit. This point is illustrated further in the TCDM by the geo-exchange systems,

22 resulting in an additional: $11.9 \%, 12.2 \%$, and $21.8 \%$ of the total cooling demand being met by

23 GSHP for the mid-rise, high-rise, and school, respectively. The increase in TCDM is a result of 
1 the geo-exchange system's artificially inflated cooling capacity, due to a pre-cooled bore-field.

2 The school's TCDM is nearly double that of the mid-rise and high-rise, as a result of the school's

3 smaller hybrid system size (smaller bore-field/soil volume). When evaluating the ACE for each

4 building case, there is a negligible impact observed from an emissions perspective, resulting in a

5 minor increase in annual $\mathrm{CO}_{2}$ emitted, of just under $1 \%$.

6 Table 8: Shoulder season summary of mid-peak/peak power reduction potential, ACE increase, 7 8

\begin{tabular}{ccccc}
\hline Building & $\begin{array}{c}\text { Peak Power } \\
\text { Reduction (\%) }\end{array}$ & $\begin{array}{c}\text { Mid-Peak Power } \\
\text { Reduction (\%) }\end{array}$ & $\begin{array}{c}\text { ACE Increase } \\
(\%)\end{array}$ & TCDM (\%) \\
\hline Mid-Rise & 16.3 & 16.6 & 0.5 & 53.7 \\
High-Rise & 14.4 & 14.9 & 0.9 & 48.2 \\
School & 24.4 & 24.7 & 0.4 & 56.4 \\
\hline
\end{tabular}

\subsubsection{Peak Season Operation}

11 The same analysis was repeated for a peak season operating bracket to determine how the bore-

12 field pre-conditioning affects the hybrid system dynamics in a period of typically high cooling

13 load density. It can be seen in Figure 8 that pre-cool strategy impact on the systems annual 14 energy consumption is sensitive to time of month. Both the mid-rise (Figure 8a) and high-rise 15 (Figure 8b) exhibit a similar trend which resulted from the shoulder season operating bracket, 16 where energy consumption increases for lower pre-cool durations and begins to decrease for 17 longer periods. What differs from peak season results is that both the mid-rise and high-rise 18 AECC is greater than the shoulder season simulation, resulting in an AECC increase of $8.0 \%$ and $196.5 \%$ for the mid-rise and high-rise, respectively. This consumption increase is a result of the 20 high cooling load density during the peak season time bracket, degrading the thermal impact the 
1 pre-cool has on the bore-field due to a greater amount of heat being injected into the ground to

2 satisfy cooling demands.

3 The school (Figure 8c) shows a positive impact for a peak season pre-cool, showing a degrading

4 energy consumption trend for pre-cool durations greater than four hours, resulting in a minor

5 AECC increase of $0.7 \%$. The school is able to benefit from peak season operation due to lower

6 cooling load density in this time frame (illustrated in Figure 6c), due to the unique occupancy

7 pattern attributed to the educational facility. With the reduced thermal demand and the

8 integration of an OGPC strategy the geo-exchange system was able to supply a larger percentage

9 of cooling demand in a more efficient manner.
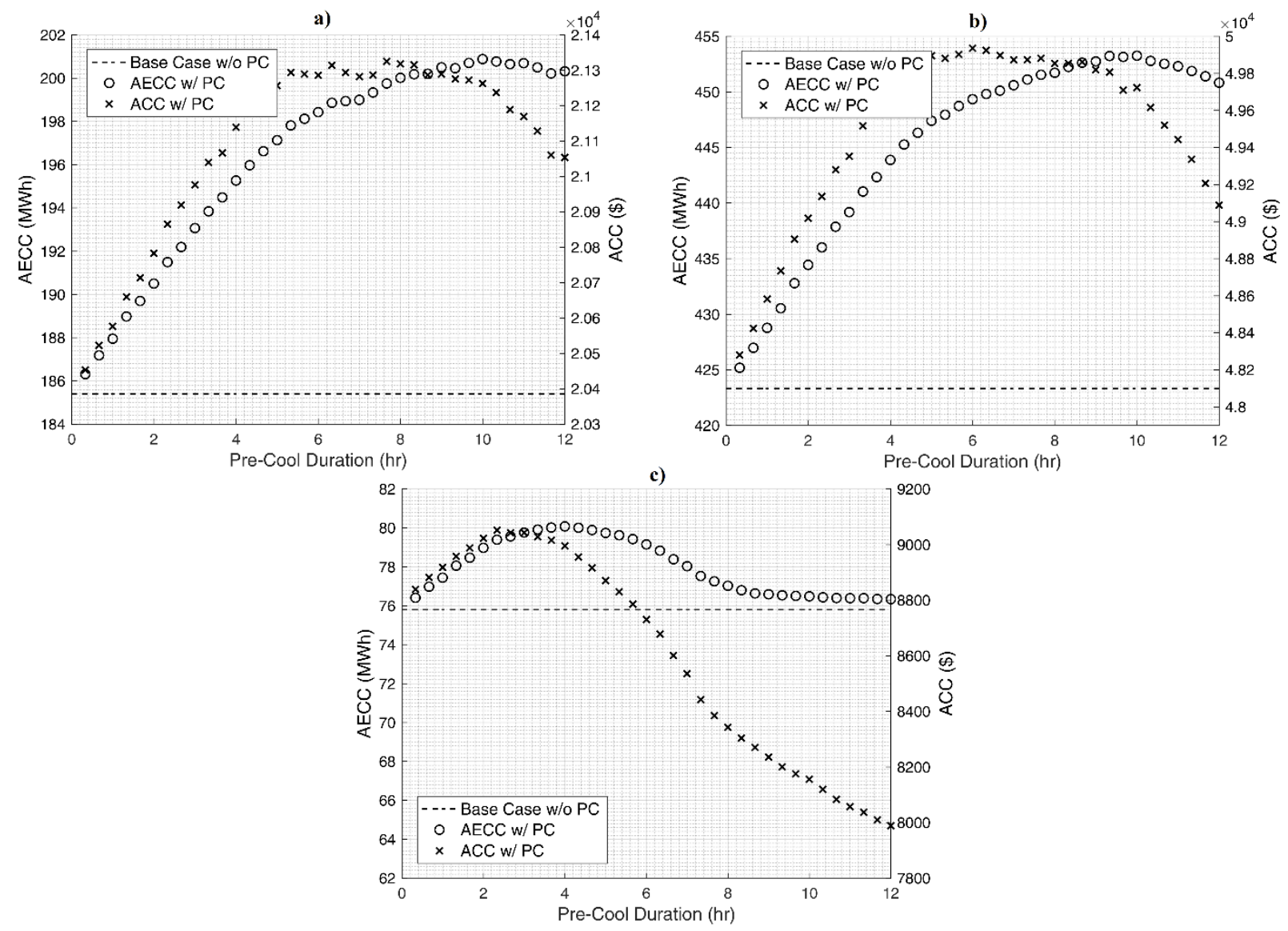

11 Figure 8: AECC and ACC for PS operation versus pre-cool duration for buildings (a) mid-rise,

(b) high-rise, and (c) school 
2 For both the mid-rise (Figure 8a) and high-rise (Figure 8b), peak season pre-conditioning

3 provides no economic benefit in the form of a reduction in operating costs when the TOU

4 structure in Section 2.2.2 is implemented. The school (Figure 8c) shows a significant cost

5 reduction for off-peak pre-conditioning with a minimum pre-cool duration of approximately five

6 hours to break even with the operating cost associated with base case control scheme. The

7 HGSHP system shows the greatest cost savings at a full 12 hour pre-cool, with an ACC

8 reduction of $9.1 \%$. The ability to generate operational cost savings is limited by the energy prices

9 associated to the TOU structure utilized in the cost computation. Although the potential savings

10 are limited for the mid-rise and high-rise, the proposed operating strategy still provides potential

11 for load leveling capabilities for all three building cases.

12 Table 9 summarizes the results for the mid-peak/peak power reduction potential for the peak

13 season pre-cool operating schedule. The results show a positive impact from a mid-peak/peak

14 power shaving perspective for all three building cases; resulting in reductions of $10.4 \% / 8.8 \%$,

$158.8 \% / 8.7 \%$, and $25.5 \%$ / 33.9\% for the mid-rise, high-rise, and school, respectively. However,

16 the mid-rise and high-rise suggest a mid-peak/peak reduction approximately half that of a

17 shoulder season pre-cool schedule (Table 8, Section 3.3.1). This result is attributed to an increase

18 in the frequency of cooling requirements during peak season. With an increase in cooling

19 demand, the thermal benefit provided by the OGPC strategy is degraded due to the increased rate

20 of heat rejection to the building's bore-field. This occurrence is further illustrated in the TCDM

21 increase for the three buildings; resulting in an additional $8.8 \%, 9.0 \%$, and $21.9 \%$ for the mid-

22 rise, high-rise, and school, respectively. The mid-rise and high-rise building's TCDM increase is

23 approximately $25 \%$ less when compared to a shoulder season pre-cool schedule. 
Table 9: Peak season summary of mid-peak/peak power reduction potential, ACE increase, and resulting TCDM for the mid-rise, high-rise, and school buildings

\begin{tabular}{ccccc}
\hline Building & $\begin{array}{c}\text { Peak Power } \\
\text { Reduction (\%) }\end{array}$ & $\begin{array}{c}\text { Mid-Peak Power } \\
\text { Reduction (\%) }\end{array}$ & $\begin{array}{c}\text { ACE Increase } \\
(\%)\end{array}$ & TCDM (\%) \\
\hline Mid-Rise & 8.8 & 10.4 & 4.4 & 50.5 \\
High-Rise & 8.7 & 8.8 & 3.1 & 44.9 \\
School & 33.9 & 25.5 & -15.0 & 56.4 \\
\hline
\end{tabular}

5 When considering the ACE, the mid-rise and high-rise show minor increases in total $\mathrm{CO}_{2}$

6 emitted; 4.4\% and 3.1\%, respectively. This result stems from the degraded pre-cool benefit

7 caused by higher cooling load density in peak season. When evaluating the school, the

8 simulations indicate a potential $15 \%$ reduction in total $\mathrm{CO}_{2}$ emitted. The school shows a $15 \%$

9 savings in $\mathrm{CO}_{2}$ emitted due to the reduced cooling demand in peak season (lower building

10 occupancy). In addition, there is a greater difference between the off-peak/peak emissions factors

11 during the peak season timeframe, generating a more significant carbon emissions reduction for 12 each kilowatt of electricity consumption deferred to an off-peak operating bracket.

\subsubsection{Full Season Operation}

14 The control algorithm was modified to restrict the OGPC operating strategy to a full season

15 period, where the predicted results for $\mathrm{AECC}$ and $\mathrm{ACC}$ with respect to the variation in pre-cool 16 duration are presented in Figure 9. It can be seen from Figure 9 that all three buildings show a 17 positive impact in energy consumption for a pre-cool duration greater than eight, nine, and four 18 hours for the mid-rise, high-rise and school, respectively. Both the mid-rise (Figure 9a) and high19 rise (Figure 9b) show a positive impact for full season operation but still result in a more 20 substantial AECC for a 12 hour pre-cool, with a $9.1 \%$ and $7.4 \%$ increase, respectively. The 21 school (Figure 9c) results in a minor 1.2\% increase in AECC for a maximum pre-cool duration. 

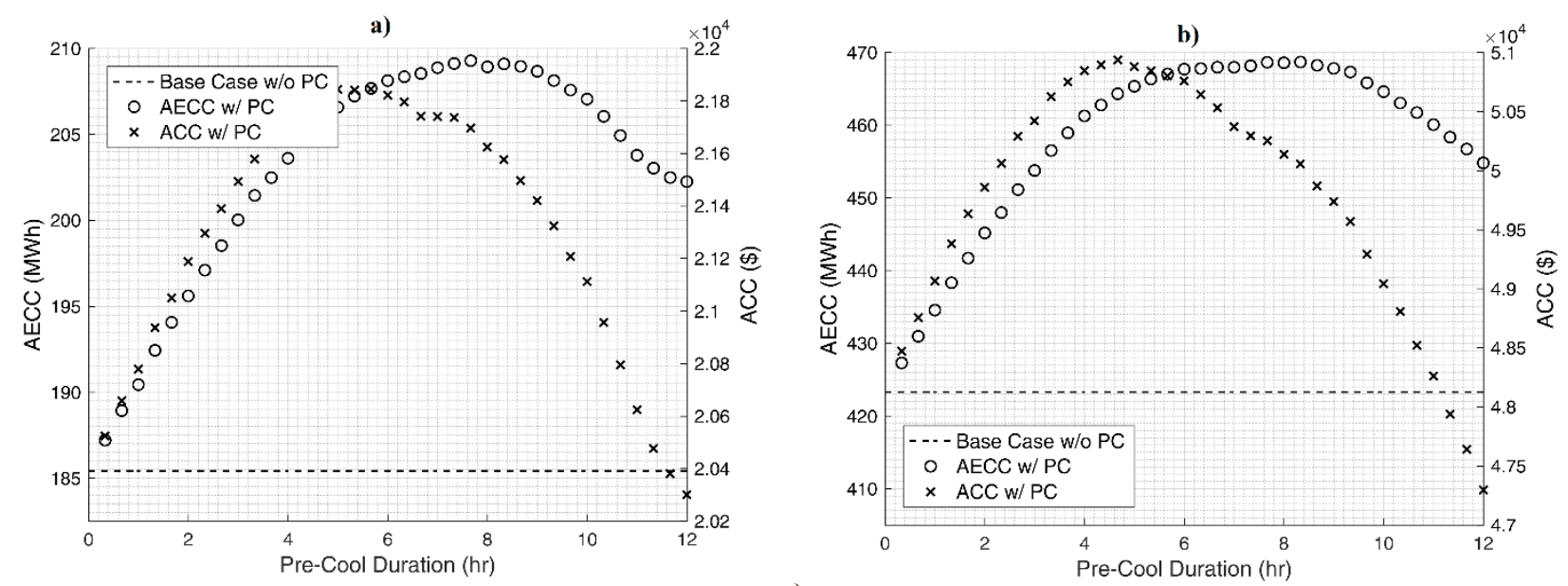

c)

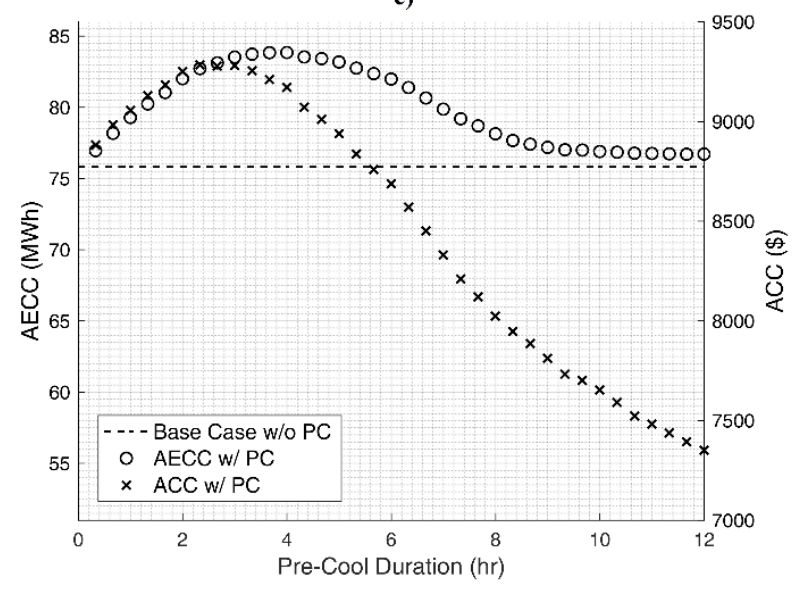

Figure 9: AECC and ACC for FS operation versus pre-cool duration for buildings (a) mid-rise,

The mid-rise (Figure 9a) and high-rise (Figure 9b) buildings require close to the maximum precool duration to obtain any operational cost savings, resulting in the largest ACC reduction of $0.4 \%$ and $1.7 \%$, respectively. The lower magnitude of annual cooling cost savings are a result of

8 the inclusion of the peak season operation within the full season timeframe, previously shown to

9 be less favorable to the mid-rise and high-rise buildings. To elevate the cost savings associated

10 with both of the multi-residential buildings peak season operation should be omitted from the 11 operating schedule, putting precedence on shoulder and mid-season operation. From Figure 9c, it 12 is clear that the school is substantially impacted by a full season operating schedule, with the 
1 predicted minimum pre-cool duration being approximately five hours, the system accomplishes a

$216.4 \%$ savings in operating cost for a pre-cool duration of 12 hours.

3 Table 10 summarizes the simulation results for the full season operating schedule, indicating

4 great potential from mid-peak/peak power reduction: $26.6 \% / 25.3 \%, 23.3 \% / 23.6 \%$, and $49.8 \%$

$5 / 58.5 \%$ for the mid-rise, high-rise, and school, respectively. The school model indicates

6 approximately double the mid-peak/peak reduction potential (compared to the mid-rise and high-

7 rise) as a result of its unique cooling demand profile and ideally sized hybrid system (smaller

8 bore-field/soil volumes). The combination of these two factors allows the school to exploit the

9 thermal benefit introduced by the pre-conditioning strategy more effectively. This occurrence is

10 further illustrated in the TCDM increase for each building case, resulting in an additional $20.7 \%$,

$1121.3 \%$, and $43.7 \%$ for the mid-rise, high-rise, and school, respectively. The school's TCDM

12 increase is approximately double the simulation results for the mid-rise and high-rise buildings.

13 Table 10: Full season summary of mid-peak/peak power reduction potential, ACE increase, and 14 15

\begin{tabular}{ccccc}
\hline Building & $\begin{array}{c}\text { Peak Power } \\
\text { Reduction (\%) }\end{array}$ & $\begin{array}{c}\text { Mid-Peak Power } \\
\text { Reduction (\%) }\end{array}$ & $\begin{array}{c}\text { ACE Increase } \\
(\%)\end{array}$ & TCDM (\%) \\
\hline Mid-Rise & 25.3 & 26.6 & 4.9 & 62.5 \\
High-Rise & 23.6 & 23.3 & 4.1 & 57.2 \\
School & 58.5 & 49.8 & -14.5 & 78.3 \\
\hline
\end{tabular}

16

17 When evaluating the ACE for the three building cases in full season, consistent trends occur

18 when compared to peak season operation. The mid-rise and high-rise indicate minor increases in

$19 \mathrm{CO}_{2}$ emitted, $4.9 \%$ and $4.1 \%$, respectively. With the school model indicating a potential $14.5 \%$

20 reduction in annual carbon emissions. The school with a full season operating schedule shows 
1 less potential for $\mathrm{CO}_{2}$ emissions (compared to peak season) due to the inclusion of the shoulder

2 season pre-cool timeframe.

3 The economic optimization methodology utilized to size the hybrid geo-exchange systems for all

4 of the building cases indicated a common advantage for the three suggested pre-cool schedules.

5 The optimal hybrid systems resulted in designs that are sized to meet less than $25 \%$ of peak 6 cooling demand. These designs physically equate to a reduced ground-loop requirement and

7 reduction in capital cost, compared to a non-hybridized system. Utilizing the OGPC strategy

8 allowed for an augmentation of the GSHP system's cooling capacity. With this augmentation,

9 the resulting optimal hybrid systems are capable of supplying a larger portion of demand over

10 the cooling season. The advantage of this physical response introduced by the pre-cool strategy

11 is that future hybrid designs can be strategically sized to further reduce ground-loop

12 requirements (improving economics by reducing capital cost) while meeting greater portions of

13 total cooling demand; taking full advantage of the potential to reduce operating costs and carbon

14 emissions.

\subsubsection{Additional Building Cases}

16 Table 11 presents a summary of six additional building cases that were considered: a private 17 school, high-rise condominium, hospital, transit facility, fast-food restaurant, and restaurant. The

18 private school and the high-rise condominium indicated trends that are consistent with the results

19 discussed above. It can be observed that the building cases that indicate a positive impact from

20 application of an OGPC control strategy are those with hybrid systems sized to meet smaller

21 portions of peak cooling demand. Thus, buildings with small shave factors indicated the greatest

22 potential for a reduction in peak power consumption and operational cost. 
1 The hospital, transit facility, fast-food restaurant, and restaurant show no significant benefit to

2 the integration of an OGPC strategy for the optimally sized HGSHP systems. Both the hospital 3 and transit facility indicate minor benefits (under 5\%) with regard to peak power reduction and 4 total cooling supplied by the geo-exchange system. When considering both the fast-food 5 restaurant and restaurant, the proposed control strategy indicates no benefit at all. This result is 6 due to the hybrid systems for the aforementioned buildings being sized to meet a greater portion 7 of peak cooling demand (lager shave factor design parameter). As the shave factor parameter is 8 increased, the ground-loop length increases, GSHP system capacity increases, and the auxiliary 9 ASHP capacity decreases. Thus hybrid systems sized to meet larger portions of peak demand 10 (smaller auxiliary cooling capacity and larger ground-loop lengths) result in excessive energy 11 consumption with insignificant GSHP operating benefit; resulting from the negligible thermal 12 impact on the bore-field, due to large bore-field/soil volumes.

13 The results presented in Table 11 clearly indicate the benefits associated to the OGPC strategy 14 are sensitive to the hybrid system proportions. This trend provides valuable insight to the hybrid 15 optimization process; systems sized to meet smaller portions of peak cooling demand indicate 16 strong potential for a reduction in ACC, ACE, and peak power consumption. This information 17 can be further utilized by feeding back into the economic optimization methodology presented in 18 [9]. Incorporating the pre-cool control strategy into the hybrid design procedure introduces the 19 advantage of allowing for additional dimensions of optimization. With this addition, the 20 optimization process can be expanded to maximize the operational cost savings. Moreover, the 21 OGPC strategy incorporated into the hybrid optimization design introduces the advantage of 22 further improving the economic appeal of a hybrid geo-exchange system as a sustainable energy 23 alternative. 
Table 11: Summary of results for additional building case studies

\begin{tabular}{|c|c|c|c|c|c|c|c|}
\hline \multicolumn{2}{|l|}{ Building } & $\begin{array}{l}\text { AECC } \\
(\mathrm{MWh})\end{array}$ & $\begin{array}{l}\mathrm{ACC} \\
(\$)\end{array}$ & $\begin{array}{c}\mathrm{ACE} \\
\left(\mathrm{kg}-\mathrm{CO}_{2}\right)\end{array}$ & $\begin{array}{l}\text { Peak } \\
\text { Power } \\
(\mathrm{MWh})\end{array}$ & $\begin{array}{l}\text { Mid-Peak } \\
\text { Power } \\
\text { (MWh) }\end{array}$ & $\begin{array}{c}\text { TCDM } \\
(\%)\end{array}$ \\
\hline \multirow{4}{*}{$\begin{array}{l}\text { Private School } \\
\qquad \alpha=0.29 \\
168.2 \mathrm{~kW} \text { peak }\end{array}$} & $\mathrm{BC}$ & 67.2 & 8341.3 & 4790.2 & 23.7 & 25.1 & 59.6 \\
\hline & SS & $+0.8 \%$ & $-5.6 \%$ & $-9.2 \%$ & $-22.0 \%$ & $-20.7 \%$ & 71.6 \\
\hline & PS & $+4.6 \%$ & $-3.3 \%$ & $+1.1 \%$ & $-20.2 \%$ & $-15.3 \%$ & 68.8 \\
\hline & FS & $+5.5 \%$ & $-9.1 \%$ & $-8.8 \%$ & $-41.9 \%$ & $-36.2 \%$ & 80.9 \\
\hline \multirow{2}{*}{$\begin{array}{l}\text { High-Rise } \\
\text { Condominium }\end{array}$} & $\mathrm{BC}$ & 248.1 & 26813.0 & 16414.2 & 57.3 & 55.4 & 57.0 \\
\hline & SS & $+5.3 \%$ & $-2.3 \%$ & $+0.3 \%$ & $-12.1 \%$ & $-12.6 \%$ & 68.2 \\
\hline$\alpha=0.30$ & PS & $+10.1 \%$ & $+1.2 \%$ & $+5.1 \%$ & $-1.8 \%$ & $-2.1 \%$ & 59.4 \\
\hline $314.4 \mathrm{~kW}$ peak & FS & $+17.4 \%$ & $-0.9 \%$ & $+5.9 \%$ & $-15.4 \%$ & $-17.1 \%$ & 71.6 \\
\hline \multirow{4}{*}{$\begin{array}{c}\text { Hospital } \\
\alpha=0.36 \\
375.0 \mathrm{~kW} \text { peak }\end{array}$} & $\mathrm{BC}$ & 324.2 & 34815.4 & 21145.9 & 73.0 & 70.6 & 60.3 \\
\hline & SS & $+14.3 \%$ & $+10.0 \%$ & $+9.7 \%$ & $-2.5 \%$ & $-3.1 \%$ & 62.0 \\
\hline & PS & $+15.9 \%$ & $+11.6 \%$ & $+13.0 \%$ & $-1.0 \%$ & $-1.3 \%$ & 61.4 \\
\hline & FS & $+30.0 \%$ & $+21.3 \%$ & $+22.7 \%$ & $-3.1 \%$ & $-4.3 \%$ & 63.2 \\
\hline \multirow{3}{*}{$\begin{array}{l}\text { Transit Facility } \\
\qquad \alpha=0.42\end{array}$} & $\mathrm{BC}$ & 187.7 & 24047.1 & 13688.3 & 74.1 & 72.2 & $\begin{array}{l}64.6 \\
\end{array}$ \\
\hline & SS & $+15.3 \%$ & $+9.1 \%$ & $+9.3 \%$ & $-1.5 \%$ & $-0.3 \%$ & 65.7 \\
\hline & PS & $+16.3 \%$ & $+10.0 \%$ & $+12.0 \%$ & $-0.4 \%$ & $-0.4 \%$ & 65.2 \\
\hline 239.4 kW peak & FS & $+31.3 \%$ & $+19.2 \%$ & $+21.3 \%$ & $-1.7 \%$ & $-1.2 \%$ & 66.3 \\
\hline \multirow{2}{*}{$\begin{array}{l}\text { Fast-Food } \\
\text { Restaurant }\end{array}$} & $\mathrm{BC}$ & 123.7 & 12744.7 & 8194.1 & 22.3 & 24.7 & 87.0 \\
\hline & SS & $+7.5 \%$ & $+5.8 \%$ & $+5.0 \%$ & $0.0 \%$ & $0.0 \%$ & 87.0 \\
\hline$\alpha=0.60$ & PS & $+7.7 \%$ & $+6.0 \%$ & $+6.3 \%$ & $0.0 \%$ & $0.0 \%$ & 87.0 \\
\hline $104.0 \mathrm{~kW}$ peak & FS & $+14.9 \%$ & $+11.8 \%$ & $+11.3 \%$ & $0.0 \%$ & $0.0 \%$ & 87.0 \\
\hline \multirow{3}{*}{$\begin{array}{c}\text { Restaurant } \\
\alpha=0.65\end{array}$} & BC & 106.0 & 10784.9 & 6845.5 & 17.9 & 20.2 & 91.4 \\
\hline & SS & $+6.8 \%$ & $+5.4 \%$ & $+4.7 \%$ & $0.0 \%$ & $0.0 \%$ & 91.4 \\
\hline & PS & $+7.0 \%$ & $+5.6 \%$ & $+5.8 \%$ & $0.0 \%$ & $0.0 \%$ & 91.4 \\
\hline $92.6 \mathrm{~kW}$ peak & FS & $+14.1 \%$ & $+10.9 \%$ & $+10.5 \%$ & $0.0 \%$ & $0.0 \%$ & 91.4 \\
\hline
\end{tabular}




\section{Conclusions}

2 The scope of this paper is to provide a preliminary analysis of a novel control strategy for the

3 application of hybrid geo-exchange systems. The analysis aimed to demonstrate the positive

4 impact that proactive pre-conditioning of a bore-field can have on system performance.

5 Employing both a thermal pre-conditioning scheme in tandem with TOU conscious control, this

6 study proposes a multifaceted methodology to address system economics through improved

7 operating efficiency and aid in the balancing of the electrical grid, at negligible capital 8 investment.

9 In this study, a numerical performance prediction model was developed using MATLAB to 10 characterize the performance of HGSHP systems associated to nine real building cases. The 11 model was used to simulate the hybrid geo-exchange systems response when controlled by the 12 proposed OGPC control strategy for shoulder, peak, and full season operating schedules. The 13 following is a summary of the significant findings and conclusions determined from this 14 analysis:

15 Shoulder Season Operation:

16 - The mid-rise and high-rise buildings showed their largest financial benefit, obtaining 17 an annual cooling cost savings of just under $4 \%$ for less than a $1 \%$ increase in energy 18 consumption.

- Reductions ranging from $17 \%$ to $25 \%$ of mid-peak/peak power consumption were accomplished, with an increase total cooling demand met by the GSHP of approximately $12 \%$ for the mid-rise/high-rise, and $22 \%$ for the school.

- Simulations indicate no potential for emissions savings, resulting in minor increase of just under $1 \%$ of $\mathrm{CO}_{2}$ emitted for all three building cases. 
Peak Season Operation:

- The impact the OGPC has on the hybrid geo-exchange systems performance is extremely sensitive to the buildings thermal load characteristics.

- The mid-rise and high-rise showed no financial incentive due to the high load density in the operating time frame resulting in the degradation of the pre-cool thermal benefit, as a result of an increase of heat injection to the bore-field.

- Although the mid-rise and high-rise showed no financial gain, a notable midpeak/peak power reduction and increase in total cooling demand met by the GSHP were observed.

- The school indicates a potential $15 \%$ reduction in total $\mathrm{CO}_{2}$ emitted, due to the combination of reduced cooling demand (lower building occupancy) in addition to there being a greater difference between the off-peak/peak emissions factors, during peak season operation.

Full Season Operation:

- Minor operating cost savings for both the mid-rise and high rise were observed. For further cost improvement, peak season operation should be excluded and additional focus should be placed on shoulder and mid-season operation.

- The school showed a predicted operating cost savings of over $16 \%$ with just over a $1 \%$ increase in energy consumption, while reducing mid-peak/peak power consumption by approximately 50\% - 59\% with the GSHP meeting an additional $44 \%$ of the total cooling demand. 
- The OGPC strategy significantly impacts the school due to the unique thermal load distribution, resulting from the occupancy pattern specific to an educational institution (lower summer loads).

This study demonstrated the potential for improving the economics of geo-exchange through the integration of a TOU-conscious control strategy. In addition, the potential for peak power shaving and a reduction in carbon emissions has been demonstrated.

Further research could be of benefit. A parametric study is recommended to evaluate the sensitivity of the conclusions drawn for the various building cases. Secondly, an experimental analysis should be conducted and compared to the results of this paper; experimentally quantifying the impact of an OGPC strategy. Future work in this research is the integration of higher level control techniques to optimize the operational cost savings, peak power shaving, and carbon emissions reduction potential introduced by an OGPC strategy.

\section{Acknowledgements}

The authors would like to acknowledge Dr. Stanley Reitsma of GeoSource Energy Inc. for advising the research and providing technical expertise. The authors would also like to thank the Faculty of Engineering and Architectural Science at Ryerson University, Ontario Graduate Scholarship, and the Natural Sciences and Engineering Research Council of Canada (NSERC) for their financial support.

\section{References}

[1] Natural Resource Canada, "Energy Use Data Handbook Table," 2013. [Online]. Available: http://oee.nrcan.gc.ca/corporate/statistics/neud/dpa/showTable.cfm?type=HB\&sector=aaa $\&$ juris $=$ ca\&rn $=2 \&$ page $=6 \& C F I D=30320730 \&$ CFTOKEN . [Accessed 14 May 2015]. 
[2] Afram, A. and Janabi-Sharifi, F., "Theory and application of HVAC control systems- A review of model predictive control (MPC)," Building and Environment, vol. 72, pp. 343$335,2014$.

[3] U.S. Energy Information Administration, “ Monthly engery review: energy consumption by sector", 2012. [Retrived Online: May 31 ${ }^{\text {st }}$, 2016]. Avaialbe:

http://www.eia.gov/totalenergy/data/monthly/\#consumption

[4] Canadian GeoExchange Coalition, “What is GeoExchange?", 2016. [Online]. Available: http://geo-exchange.ca/en/what_is_geoexchange_p10.php

[5] Yannopoulos, S.I., Lyberatos, G., Theodossion, N., Li, W., Valipour, M., Tamburrino, A., and Angelakis, A.N., "Evolution of Water Lifting Devices (Pumps) over the Centuries Worldwide", Water, vol. 7, pp. 5031 - 5060, 2015.

[6] Esen, H., Inalli, M., and Esen, M., "Numerical and experimental analysis of a horizontal ground-coupled heat pump system", Building and Environment, vol. 42, pp. 1126 - 1134, 2007.

[7] Esen, M. and Yuksel, T., "Experimental evaluation of using renewable energy sources for heating a greenhouse", Energy and Buildings, vol. 65, pp. 340 - 351, 2013.

[8] Kavanaugh, S. P. and Rafferty, K. R. , Ground-Source Heat Pumps: Design of Geothermal Systems for Commercial and Instututional Buildings, 1997.

[9] Alavy, M., Nguyen, H.V., Leong, W.H., and Dworkin, S.B., "A methodology and computerized approach for optimizing hybrid ground source heat pump system design", Renewable Energy, vol. 57, pp. 404-412, 2013.

[10] Nguyen, H.V., Law , E., Alavy, M., Walsh, P.R., Leong, W.H., and Dworkin, S.B., "An analysis of the factors affecting hybrid ground-source heat pump installation potential in North America”, Applied Energy, vol. 125, pp. 28-38, 2014.

[11] Hanova, J., Dowlatabadi, H., and Mueller, L., "Ground source heat pump systems in Canada; economics and GHG reduction potential", Resources for the Future, RFF DP 07$18,2007$.

[12] Esen, H., Inalli, M., and Esen, M., "Techno-economic appraisal of ground source heat pump system for a heating season in eastern Turkey", Energy Conversion and Management, vol. 47, pp. 1281-1297, 2006.

[13] Hackel, S and Pertzborn, A, "Effective design and operation of hybrid ground-source heat pumps: three case studies," Energy and Buildings, vol. 43, pp. 3497-3504, 2011.

[14] ASHRAE, Commercial/Institutional Ground-Source Heat Pump Engineering Manual, American Society of Heating, Refrigerating and Air-Conditioning Engineers Inc., 1995.

[15] Montagud, C., Corberan, J.M., and Montero, A., "In situ optimization methodology for the water circulation pumps frequency of ground source heat pump systems," Energy and Buildings, vol. 68, pp. 42-53, 2014. 
[16] Gang, W. and Wang, J., "Predictive ANN model of ground heat exchanger for the control of hybrid ground source heat pump systems," Applied Energy, vol. 112, pp. 1146-1153, 2013.

[17] Sagia, Z. and Rakopoulos, C., "New control strategy for a hybrid ground source heat pump system couple to a closed circuit cooling tower," Journal Of Applied Mechanical Engineering, vol. 1(2), pp. 1-8, 2012.

[18] Dounis, A.I. and Caraiscos, C., "Advanced control systems engineering for energy and comfort management in a building environment," Renewable and Sustainable Energy Reviews, vol. 13, pp. 1246-1261, 2009.

[19] Nam, Y.J., Gao, X.Y., Yoon, S.H., and Lee, K.H., "Study on the performance of a ground source heat pump system assisted by solar thermal storage", Energies, Vol. 8, 1337813394, 2015.

[20] Esen, H., Esen, M., and Ozsolak, O., "Modelling and experimental performance anakysis of a solar-assisted ground source heat pump system", Journal of Experimental \& Theoretical Artificial Intelligence, doi: 10.1080/0952813X.2015.1056242, pp. 1 - 17, 2015.

[21] Janssen, E., Zhang, D., and Van Seters, T., Toronto and Region Conservation Authority Technical Report, "Performance assessment of urban geo-exchange projects in the greater Toronto area.", 2015.

[22] Carvalho, A.D., Moura, P., Vaz, G.C, and de Almedia, A.T., "Ground source heat pumps as high efficient solutions for building space conditioning and for integration in smart grids," Energy Conversion and Management, Vol. 103, pp.991-1007, 2015.

[23] eQUEST., “the Quick Energy Simulation Tool”, 2016. [Online]. Available:

http://doe2.com/equest/

[24] MathWorks Inc., "MATLAB", 2016. [Online]. Available:

www.mathworks.com.

[25] Valipour, M., Banihabib, M.E., and Behbahani, S.M.R., "Comparison of the ARMA, ARIMA, and the autoregressive artificial neural network models in forecasting the monthly inflow of Dez dam reservoir", Journal of Hydrology, vol. 476, pp. 433 - 441, 2013.

[26] Valipour, M., "Optimizations of neural networks for precipitation analysis in humid region to detect drought and wet year alarms", Meteorological Applications, vol. 23 6), pp. 91 - 100, 2016. doi: 10.1002/met.1533

34 [27] Khasraghi, M.M., Sefidkouhi, M.A.G., and Valipour, M., "Simulation of open- and closed end border irrigation systems using SIRMOD", Archives of Agronomy and Soil Science, vol. 61, no. 7, pp. 929 - 941, 2015. doi: 10.1080/03650340.2014.981163 
[28] Valipour, M., "Sprinkle and Trickle Irrigations System Design Using Tapered Pipes for Pressure Loss Adjusting”, Journal of Agricultural Science, vol. 4, pp. 1916 - 9752, 2012. doi: $10.5539 /$ jas.v4n12p125

[29] Valipour, M., Sefidkouhi, M.A.G, and Eslamian, S., "Surface irrigation simulation models: a review", Int. J. Hydrology Science and Technology, vol. 5, no. 1, pp. 51 - 70, 2015.

[30] Riestma S, Personal communication with GeoSource Energy Incorperated, 2015.

[31] Esen, H., Inalli, M., and Esen, M., "A techno-economic comparison of ground-coupled and air-coupled heat pump systems for space cooling," Building and Environment, vol. 42, pp. 1955-1965, 2007.

[32] W. Alzahrani, "Experimental study of the performance of a vertical and horizontal ground loops coupled to a ground source heat pump system", MASc Thesis, Department of Mechanical and Industrial Engineering, Ryerson University, Toronto, Ontairo, Canada, 2013.

[33] Ontario Energy Board, "Time-of-use (TOU) prices”, 2015. [Online]. Available: http://www.ontarioenergyboard.ca/OEB/Consumers/Electricity/Electricity+Prices.

[34] Independent Electricity System Operator, "Generator Output by Fuel Type Hourly Report," 2016. [Online]. Available:

http://reports.ieso.ca/public/GenOutputbyFuelHourly/.

[35] Mallia, E., and Lewis, G. , "Life cycle greenhouse gas emissions of electricity generation in the province of Ontario, Canada," The International Journal of Life Cycle Assessment, vol. 18, no. 2, pp. 377 - 391, 2013.

[36] U.S. Energy Information Administration, "Carbon dioxide is produced per kilowatthour when generating electricity with fossil fuels," 2016. [Online]. Available:

https://www.eia.gov/tools/faqs/faq.cfm?id=74\&t=11.

[37] Covenant of Mayors, "Technical annex to teh SEAP template instructions document: The emissions factors," 2016. [Online]. Available:

http://www.eumayors.eu/IMG/pdf/technical_annex_en.pdf.

[38] AECOM, "Carbon emission factors for fuels-Methodology and values for2013 \& 2016," 2010. [Online]. Available:

[39] Wang L., Zhang J., Min H., Xu L. (2015). “Optimal control of cooling tower in hybrid ground-source heat pump systems for hotel buildings", Proceedings of the 2015 ICADME Conferenc.

http://www.zerocarbonhub.org/resourcefiles/Carbon Emission Factors for Fuelsmethodology and valuesfor 2013 and 2016.pdf.

36 [40] TRNSYS Inc., "TRNSYS Transient System simulation Tool" 2016. [Online]. Available: 
WWW.trnsys.com.

2 [41] Govermnet of Canada, "Canadian Climate Normals 1981-2010 Station Data”, 2016. 3 [Online]. Avaialbe:

4 http://climate.weather.gc.ca/climate_normals/results_1981_2010_e.html?searchType=stn 5 Prov\&lstProvince $=$ ON\&txtCentralLatMin $=0 \&$ txtCentralLatSec $=0 \&$ txtCentralLongMin $=$ $0 \&$ txtCentralLongSec $=0 \& \operatorname{stnID}=5051 \& \operatorname{dispBack}=0$ 